\title{
1 Evidence of selection, adaptation and untapped diversity in Vietnamese rice landraces
}

\section{2}

3 Janet Higgins ${ }^{1}$, Bruno Santos ${ }^{2}$, Tran Dang Khanh ${ }^{3,4}$, Khuat Huu Trung ${ }^{3}$, Tran Duy Duong ${ }^{3}$, Nguyen

4 Thi Phuong Doai ${ }^{3}$, Nguyen Truong Khoa ${ }^{3}$, Dang Thi Thanh $\mathrm{Ha}^{3}$, Nguyen Thuy Diep ${ }^{3}$, Kieu Thi

$5 \quad$ Dung ${ }^{3}$, Cong Nguyen $\mathrm{Phi}^{3}$, Tran Thi Thuy ${ }^{3}$, Nguyen Thanh Tuan ${ }^{4}$, Hoang Dung Tran ${ }^{6}$, Nguyen Thanh

6 Trung $^{7,9}$, Hoang Thi Giang ${ }^{3}$, Ta Kim Nhung ${ }^{3}$, Cuong Duy Tran ${ }^{3}$, Son Vi Lang ${ }^{3}$, La Tuan Nghia ${ }^{8}$,

7 Nguyen Van Giang ${ }^{4}$, Tran Dang Xuan ${ }^{5}$, Anthony Hall ${ }^{1}$, Sarah Dyer ${ }^{2}$, Le Huy Ham ${ }^{3}$, Mario Caccamo ${ }^{2}$,

8 Jose De Vega*1

9

$10 \quad{ }^{1}$ Earlham Institute, Norwich Research Park, Norwich, NR4 7UZ, UK.

112 NIAB, 93 Lawrence Weaver Road, Cambridge, CB3 0LE, UK.

$12{ }^{3}$ Agriculture Genetics Institute (AGI), Hanoi, Vietnam.

$13{ }^{4}$ Vietnam National University of Agriculture, Hanoi, 131000, Vietnam.

$14{ }^{5}$ Graduate School of Advanced Science and Engineering, Hiroshima University, Hiroshima, 739-

158529 , Japan.

$16{ }^{6}$ Faculty of Biotechnology, Nguyen Tat Thanh University, Ho Chi Minh, 72820, Vietnam.

$17{ }^{7}$ Institute of Research and Development, Duy Tan University, Da Nang, 550000, Vietnam.

$18{ }^{8}$ Plant Resource Center, An Khanh, Hoai Duc, Hanoi, 152900, Vietnam.

$19{ }^{9}$ Faculty of Pharmacy, Duy Tan University, Da Nang, 550000, Vietnam.

20

21

$22 *$ Correspondence to jose.devega@earlham.ac.uk; Earlham Institute, Norwich Research Park,

23 Norwich, NR4 7UZ, UK.

24

25 Running title: Genetic diversity of rice in Vietnam. 


\section{Abstract}

29 Vietnam possesses a vast diversity of rice landraces due to its geographical situation, latitudinal range,

30 and a variety of ecosystems. This genetic diversity constitutes a highly valuable resource at a time

31 when the highest rice production areas in the low-lying Mekong and Red River Deltas are enduring

32 increasing threats from climate changes, particularly in rainfall and temperature patterns.

34 We analysed 672 Vietnamese rice genomes, 616 newly sequenced, that encompass the range of rice

35 varieties grown in the diverse ecosystems found throughout Vietnam. We described four Japonica and

36 five Indica subpopulations within Vietnam likely adapted to the region of origin. We compared the

37 population structure and genetic diversity of these Vietnamese rice genomes to the 3,000 genomes of

38 Asian cultivated rice. The named Indica-5 (I5) subpopulation was expanded in Vietnam and contained

39 lowland Indica accessions, which had with very low shared ancestry with accessions from any other

40 subpopulation and were previously overlooked as admixtures. We scored phenotypic measurements

41 for nineteen traits and identified 453 unique genotype-phenotype significant associations comprising

42 twenty-one QTLs (quantitative trait loci). The strongest associations were observed for grain size

43 traits, while weaker associations were observed for a range of characteristics, including panicle

44 length, heading date and leaf width. We identified genomic regions selected in both Indica and

45 Japonica subtypes during the breeding of these subpopulations within Vietnam and discuss in detail

46 fifty-two selected regions in I5, which constitute an untapped resource of cultivated rice diversity.

48 Our results highlight traits and their associated genomic regions, which were identified by fine

49 phenotyping and data integration. These are a potential source of novel loci and alleles to breed a new

50 generation of sustainable and resilient rice.

52 KEYWORDS: Rice, breeding, adaptation, QTL, genetic diversity, GWAS, landraces. 


\section{Background}

56 Rice production in Vietnam is of great value for export and providing daily food for more than 96

57 million people. However, agricultural production, especially rice cultivation, is inherently vulnerable

58 to climate variability across all regions in Vietnam. Based on the records of monthly precipitation and

59 temperature from 1975 to 2014 [1], the areas of highest crop production in the low lying Mekong and

60 Red River Deltas are particularly vulnerable to the increasing threat from climate change. In 2017, the

61 total planted area of rice in Vietnam was 7.7 million hectares. This includes 4.2 million hectares in the

62 Mekong River Delta and 1.1 million hectares in the Red River Delta [2]. These are also the areas

63 where most of the population of the county is concentrated. In the Mekong River Delta, the damaging

64 effects of salinisation and drought to rice production have increasingly manifested themselves in

65 recent years [3-6].

67 Vietnam possesses a vast diversity of native and traditional rice varieties due to its geographical

68 situation, latitudinal range and diversity of ecosystems [7]. This diversity constitutes a largely

69 untapped and highly valuable genetic resource for local and international breeding programs.

70 Vietnamese landraces are disappearing as farmers switch to modern elite varieties. To limit this

71 erosion of genetic resources, several rounds of collection of landraces, particularly from the northern

72 upland areas, have been undertaken since 1987. Thousands of rice accessions have been deposited in

73 the Vietnamese National Genebank at the Plant Resources Center (PRC, Hanoi, Vietnam), together

74 with passport information detailing their traditional name and province of origin. One hundred and

75 eighty-two traditional Vietnamese accessions were selected for a genotype by sequencing (GBS)

76 study in 2014 [8]. This study yielded 25,971 single nucleotide polymorphisms (SNPs) and was used

77 to describe four Japonica and six Indica subpopulations. These subpopulations were classified by

78 region, ecosystem and grain-type using passport information (province and ecosystem) and

79 phenotyping. This dataset had subsequently been used for genome-wide phenotype-genotype

80 association studies (GWAS) relating to root development [9], panicle architecture [10], drought

81 tolerance [11], leaf development [12] and Jasmonate regulation [13]. 
83 An international effort to re-sequence Asian rice accessions known as the "3000 Rice Genomes

84 Project" (3K RGP) has provided the rice community with a better understanding of Asian rice

85 diversity and evolutionary history, as well as providing valuable knowledge to enable more efficient

86 use of these accessions for rice improvement $[14,15]$. However, only 56 of these accessions

87 originated from Vietnam, suggesting that the rice diversity within this country may not be fully

88 captured within the 3K RGP. While the original 3K RGP analysis described nine subpopulations [15],

89 subsequent reanalysis had shown that the 3K RGP could be further subdivided into fifteen

90 subpopulations [16].

91

92 In this paper, we newly sequenced 616 Vietnamese rice accessions using whole-genome sequencing

93 (WGS), most of them being native landraces. 164 of these rice accessions were in common with a

94 previous study [8] based on a genotyping-by-sequencing (GBS) approach. We supplemented

95 this dataset with all 56 Vietnamese genotypes from the 3K RGP to form a native diversity panel. We

96 analysed this diversity panel of 672 accessions to explore the history of rice breeding in Vietnam,

97 which is reflected in detectable changes in the allele frequency at sites under selection and their

98 flanking regions. We also carried out a comprehensive analysis of the population structure of the

99 combined 3,635 rice genomes obtained from joining our diversity panel and the complete 3K RGP

100 datasets. We completed a GWAS on the diversity panel with 672 accessions (and separately for the

101 Japonica and Indica subtypes within it) on thirteen phenotypes, which are available for around two-

102 thirds of the samples. Finally, we looked for regions of selection between the subpopulations within

103 Vietnam to reveal 200 regions spanning $7.8 \%$ of the genome, which might reflect their adaptation to

104 local agricultural practices and farming conditions [17]. We used a similar approach to the following

105 two studies; a comparison of upland and irrigated rice accessions to identify ecotype differentiated

106 regions related to phenotypic differences [18], and a comparison of Indica semi-dwarf modern bred

107 varieties (IndII) with taller Chinese landraces (IndI).

108 
109 Our results highlight genomic differences between traditional Vietnamese landraces, which are likely

110 the product of adaption to multiple environmental conditions and regional culinary preferences in a

111 very diverse country.

\section{Results}

\section{Sequencing rice diversity from Vietnam}

116 Whole-genome sequencing was carried out on 616 rice accessions. 511 of the accessions were

117 obtained from the PRC (Plant Resource Centre, Hanoi, Vietnam, http://csdl.prc.org.vn), together with

118 their passport data, which shows that they were collected from all eight administrative regions of

119 Vietnam (Additional file 1: Table S1). The remaining samples were obtained from AGI's collection

120 (Agricultural Genomics Institute, Hanoi, Vietnam). Three reference accessions (Nipponbare, a

121 temperate Japonica; Azucena, a tropical Japonica; and two accessions of IR64, an Indica) obtained

122 from the PRC, were included in the dataset. A total of 1,174 Giga base-pairs (Gbps) of data was

123 generated for the 616 samples representing an average sequencing depth of 30x for 36 "high

124 coverage" samples and 3x for 580 "low coverage" samples (Additional file 1: Table S1). These 616

125 newly-sequenced accessions were classified into 379 Indica and 202 Japonica subtypes, with the

126 remaining 35 (including the Aus and Basmati varieties) being classified as admixed, based on the

127 STRUCTURE [19] output for K=2 using a subset of 163,393 SNPs.

129 Population structure of rice within Vietnam

130 The population structure of rice within Vietnam was analysed using the diversity panel of 672

131 samples, comprising 616 newly sequenced accessions and 56 Vietnamese genotypes from the $3 \mathrm{~K}$

132 RGP. We assigned the 672 samples to four Japonica subpopulations and five Indica subpopulations

133 (Additional file 1: Table S1) using (i) the population structure information obtained from the

134 STRUCTURE analysis (Fig. 1), (ii) the previous characterisation of a panel of Vietnamese native rice

135 varieties using GBS [8], and (iii) the assessment of the optimal number of subpopulations (Additional

136 file 2: Figure S1) using the method described in Evanno et al. [20]. Subpopulations were named as in 
137 Phung et al. [8], except that we considered the I6 subpopulation to be part of the I3 subpopulation.

138 Although the previous study used a limited number of GBS markers, 129 of the 164 common samples

139 were assigned to the same subpopulations in both studies. Most differences were due to samples being

140 classified as admixed in either one of the studies. We classified $48(11 \%)$ of the Indica (Im), and eight

$141(4 \%)$ of the Japonica samples (Jm) as admixed. The reference varieties Nipponbare (Temperate

142 Japonica), Azucena (Tropical Japonica), and IR64 (Indica) were classified as J4, J1 and I1,

143 respectively.

145 Each Indica subpopulation contained shared ancestry (admixed components) with other Indica

146 subpopulation (Fig. 1a). The admixed components are shown in detail for the 43 samples in the I5

147 subpopulation (Fig. 1c) namely 38 samples from our dataset and the following five samples from the

148 3K RGP; IRIS 313-11384 (IRGC 127275), B184 (IRGC 135862), IRIS 313-11383 (IRGC 127274),

149 IRIS 313-10751 (IRGC 127577) and IRIS 313-11893 (IRGC 127519). The Japonica subtropical J1

150 subpopulation shared ancestry (between 0 and $25 \%$ of the genome) with the Japonica tropical J3

151 subpopulation, whereas the two temperate subpopulations, J2 and J4 shared ancestry dominantly with

152 each other. The tropical J3 subpopulation contained four samples with around 20\% of the haplotypes

153 in common with the temperate $\mathrm{J} 4$ subpopulation. Using the passport information available from the

154 PRC, the proportion of each subpopulation originating from each of the "administrative regions" of

155 Vietnam is shown in Fig. 1d. Only the I1 and I2 Indica subpopulations were collected from the

156 Mekong River Delta regions, I2 being almost exclusively grown there whereas I1 was more

157 widespread than I2. The I4 and J4 subpopulations were mainly collected from the Red River Delta

158 areas. The $\mathrm{J} 1$ and $\mathrm{J} 3$ subpopulations were closely related; the $\mathrm{J} 1$ subpopulation was predominantly

159 from the North of Vietnam whereas the J3 subpopulation was concentrated around the South-Central

160 Coast region. Small variations in the percentage of reads mapping were observed for each of the

161 subpopulations (Additional file 2: Figure S2).

162

163 A Principal Component Analysis (Fig. 2a and 2b) showed the relationship between these nine

164 Vietnamese subpopulations [16]. Concerning the Vietnamese genotypes from the 3K RGP dataset 
165 included in the diversity panel, the Indica I1 subpopulation included two XI-1B modern varieties and

166 eight admixed (XI-adm) accessions. I2 included fourteen XI-3B1 genotypes, which comprises

167 Southeast Asian accessions, and similarly, I3 and I4 included one and ten XI-3B2 genotypes,

168 respectively. Finally, I5 included five XI-adm accessions and clustered distinctly away from all the

169 other subpopulations (Fig. 2a). On the other hand, J1 included the two subtropical (GJ-sbtrp)

170 accessions from the Vietnamese 3K RGP genotypes, and J3 included one tropical (GJ-trp1) accession

171 from the Vietnamese 3K RGP genotypes (Fig. 2b). These results correlate well with the latitudinal

172 distinction between these subpopulations. J2 and J4 included two and one temperate (GJ-tmp)

173 accessions, respectively; and split into two clear subpopulations in Vietnam compared with the East

174 Asian temperate subpopulation described by the 3K RGP.

\section{Population structure of the combined 3,635 Asian cultivated rice genomes}

177612 of the 616 newly sequenced accessions from this study and the 3,023 accessions from the $3 \mathrm{~K}$

178 RGP were combined and classified into 9 and 15 subpopulations (Additional file 1: Table S2), and

179 compared with the subpopulations from the 3K RGP analysis $[15,16]$. For clarity, we used the prefix

180 Jap- and Ind- to label these subpopulations from our analysis.

182 When the combined dataset of 3,635 samples was classified into nine subpopulations (Figure S3a), we

183 found that $95 \%$ of the $3 \mathrm{~K}$ RGP accessions $(2,882$ out of 3,023$)$ were assigned into the same

184 subpopulations. The remaining 5\% lines were either (i) previously classified as admixture and our

185 analysis placed into a subpopulation, or (ii) were previously classified in a subpopulation and were

186 now classified as admixture. The 612 newly sequenced Vietnamese accessions were placed in three

187 Indica clusters (187 accessions), three Japonica clusters (176 accessions), the Basmati and Sadri

188 aromatic $\mathrm{cB}$ group (11 accessions), or the Aus cA subpopulation (one accession). In more detail, the

189 three Indica clusters included three Im accessions in the East Asian cluster (Ind-1A), seventy-six I1

190 accessions in the cluster of modern varieties of diverse origins (Ind-1B ), and 108 accessions (I2, I3

191 and Im) in the Southeast Asian cluster (Ind-3). Whereas, the three Japonica clusters included 54

192 accessions (J2, J4 and Jm) in the primarily East Asian temperate cluster (Jap-tmp), 119 accessions (J1, 
$193 \mathrm{~J} 3$ and Jm) in the Southeast Asian subtropical cluster subpopulation (Jap-sbtrp) and three J3

194 accessions in the Southeast Asian Tropical subpopulation (Jap-trp). Any remaining accession with

195 admixture components over 65\% either Indica or Japonica were classified as Ind-adm (191

196 accessions) or Jap-adm (27 accessions), respectively. Finally, the remaining accessions were

197 considered as Admix (19 accessions). Notably, all thirty-seven I5 accessions were placed in Ind-adm,

198 and ten of the sixteen J3 accessions were placed in Jap-adm.

200 When the combined dataset of 3,635 samples was reclassified into 15 subpopulations (K15_new,

201 Figure S3b), we noticed the following differences in the distribution of subpopulation compared to the

202 3K RGP analysis for the same number of 15 subpopulations (K15_3KRGP); we did not observe the

203 division of the Aus samples into cA-1 and cA-2, and we subdivided the Indica subtypes and Japonica

204 subtypes into eight and five subpopulations, respectively. A Principle Coordinate (PCO) analysis of

205 the Indica and Japonica subpopulations is shown in Fig. 3, highlighting our new eight Indica and five

206 Japonica subpopulations (In addition the Vietnamese and 3K RGP subpopulations are shown in

207 Figures S5 and S6).

208

209 The relation between the subpopulations in our comprehensive analysis (3,635 accessions) and the $3 \mathrm{~K}$

210 RGP (3,023 accessions) was as follows: (i) The Ind-1A, Ind-1B.1 and Ind-1B.2 were equivalent to

211 XI-1A, XI-1B1 and XI-1B2, respectively. Forty-three of the Vietnamese I1 accessions were in the

212 Ind-1B.1 subpopulation, and the remaining 102 I1 accessions were classified as admixed. (ii) The Ind-

2132 was equivalent to XI-2A and XI-2B, and as expected, this geographically distant South Asian

214 subpopulation was not present in Vietnam. (iii) The previously observed split of the Indica-3

215 subpopulation into 3A and 3B was also observed in our analysis, where Ind-3.1 was equivalent to XI-

$2163 \mathrm{~A}$ and did not contain any Vietnamese accessions. (iv) The remaining Ind-3.2, Ind-3.3 and Ind-3.4

217 were a rearrangement of the XI-3B1 and XI-3B2 subpopulations. (v) The 89 Vietnamese I2

218 accessions belonged to Ind-3.2, which was a subset of XI-3B1. (vi) Ind-3.3 contained 16 of the 37

219 Vietnamese I3 accessions. (vii) $72 \%$ of the accessions in Ind-3.4 were from Vietnam, which contained

22013 of the 37 I 3 accessions, 61 of the 62 I4 accessions, and all I5 accessions. Within Ind-3.4, the 
221 admixture components of I3, I4 and I5 subpopulations (Figure S7) showed that I3 accessions were

222 highly admixed, some I4 and I5 accessions were completely within Ind-3.4, while other I4 and I5

223 accessions showed admixture with Ind-3.3 (I5) or Ind.2, Ind-3.2, and Ind-3.3 (I4). To clarify these

224 relations, a principle component analysis (PCA) with a reduced number of accessions was carried out

225 using the 723 sample dataset (672 Vietnamese accessions and 51 genotypes from neighbouring

226 Southeast Asian Countries; Figure S8), this supported the close relationships of I2 with XI-3B1, I4

227 with XI-3B2, I5 with XI-adm, J1 with GJ-sbtrp, and that both J2 and J4 were within GJ-tmp.

\section{Phenotypic and genetic diversity analysis of the Vietnamese Indica and Japonica}

subpopulations

231 Phenotypic measurements for 19 traits were scored in field conditions in the Hanoi area by breeders

232 from the Agricultural Genomics Centre (AGI) for approximately two-thirds of the samples in our

233 study. For five of these traits, additional scores were also included from trials by the Vietnamese Plant

234 Resource Centre. In addition, phenotypic data were available for eleven of the traits in 38 of the 56

235 samples sourced from the 3K-RGP dataset (Additional file 1: Table S3, Table S4). Finally, the grain

236 length to grain width ratio (GL/GW) was calculated to give a total of 20 traits (Additional file 1:

237 Table S5). Scores were available for between 328 and 503 of the 672 samples (Indica subpanel, 170 -

238297 samples and Japonica subpanel, 134 - 178 samples).

240 There were significant differences in measurements between the Indica and Japonica subtypes for ten

241 of the traits; these are detailed in Additional file 1: Table S5 and histograms are shown in Fig. 4 for

242 selected phenotypes. The Indica subtypes had significantly (p-value <0.0001) higher values for grain

243 length to width ratio, leaf pubescence, culm number, culm length, and floret pubescence. In contrast,

244 the Japonica subtypes had significantly higher values for grain width, leaf width, flag leaf angle,

245 panicle length, and floret colour. The Indica I1 subpopulation (mostly elite varieties) was the most

246 phenotypically distinct when compared to the rest of the Indica samples (mostly native landraces). I1

247 samples had longer grains $(\mathrm{p}$-value $=2.2 \mathrm{e}-16)$, earlier heading date $(\mathrm{p}$-value $=9.9 \mathrm{e}-12)$, higher culm

248 strength $(\mathrm{p}$-value $=2.2 \mathrm{e}-16)$, shorter leaf length $(\mathrm{p}$-value $=2.7 \mathrm{e}-14)$ and shorter culm length $(\mathrm{p}$-value 
249 <.2e-16). Similar values were obtained when comparing I1 to just the I5 subpopulation (Fig. 4). The

250 I5 subpopulation was not phenotypically distinct (p-value $<0.001)$ from the other landrace

251 subpopulations I2, I3 and I4, except for a significantly lower measurement of leaf pubescence (p-

252 value $=0.0007$ ). The Japonica J2 subpopulation had a significantly lower grain length to width ratio

253 than $\mathrm{J} 1(\mathrm{p}$-value $=1.8 \mathrm{e}-13)$ and $\mathrm{J} 3(\mathrm{p}$-value $=5.7 \mathrm{e}-07)$. A correlation analysis carried out between the

25420 phenotypes (Additional file 2: Figure S9) showed that the highest correlation $(r=0.6)$ was

255 between leaf length and culm length (excluding the correlation between grain length to width ratio

256 and grain length and grain width). Histogram and correlation plots are available for the 13 traits used

257 for the GWAS analysis in Additional file 2: Figure S10 comparing the Indica and Japonica subtypes

258 and in Additional file 2: Figure S11 comparing subpopulations I1 and I5. Further boxplots showing

259 the phenotypic distribution according to subpopulation for culm length, grain length, grain width and

260 heading date are available in Additional file 2: Figure S12.

261

262 The Japonica subtypes had a lower nucleotide diversity $(\pi=0.000912)$ than the Indica subtypes $(\pi=$

263 0.00167). Looking at the individual subpopulations (Additional file 1: Table S6), the elite I1

264 subpopulation is the most diverse $(\pi=0.00144)$, and the I5 subpopulation is the least diverse $(\pi=$

265 0.00103). Regions of the genome with low diversity in all Indica subpopulations, and regions with

266 low diversity in specific subpopulations, were observed when plotting diversity along each

267 chromosome (Additional file 2: Figure S13). The J3 subpopulation is the most diverse of the four

268 Japonica subpopulations. $(\pi=0.000697)$. Large genomic regions with very low diversity were

269 observed in chromosomes 2, 3, 4 and 5 in all Japonica subpopulations (Additional file 2: Figure S14).

\section{Genome-wide association analysis}

272 Three independent GWAS were conducted using the full panel (672 samples, 361,191 SNPs), the

273 Indica subpanel (426 samples, 334,935 SNPs) and the Japonica subpanel (211 samples, 122,881

274 SNPs). Thirteen (13) of the 20 traits were suitable for GWAS based on the variance (CV $<56 \%$ for

275 the full panel). The full list of phenotypic measurements is available in Additional file 1: Table S3. 
276 We found 643 significant phenotype-genotype associations. These associations were organised into

27721 QTLs (Table 1, Additional file 1: Table S7). The GWAS Manhattan and Quantile-Quantile plots

278 are available in Additional file 3: Figure S17 and Additional file 4: Figure S18. The QTLs ranged

279 from $41 \mathrm{~kb}$ (16_FP) to 3,148 kb (5_GS). The 21 QTLs contained 1,730 genes and covered a total of

$28011 \mathrm{Mbp}$ over ten chromosomes, and contained 453 SNPs with a significant association to a trait in at

281 least one diversity panel (Fig. 5). The list of genes within each QTL is available in Additional file 1:

282 Table S8. Functional enrichment was found within 9 of the QTL (Additional file 1: Table S9).

283

284 Seventeen QTLs were identified in the full diversity panel significantly associated with eight traits:

285 grain length, grain width, grain length-to-width ratio, leaf width, panicle length, floret pubescence,

286 heading date and internode diameter. A further 4 QTLs associated with grain length and grain width

287 were observed only in the Japonica subpanel. Three of the QTLs, which were found in the full panel,

288 were also observed in the Indica subpanel.

The set of 3.8M SNPs (see methods), representing one SNP every 99 bases, was annotated based on

291 the potential effect of each SNP in protein function using SnpEff (Additional file 1: Table S3).

$292526,138(4.79 \%)$ of the SNPs were in genes. There were 21,639 (0.197\%) SNPs in 11,125 genes

293 classified as having a putative "High impact" effect (E.g. Exon changes, frameshifts, gene fusions or

294 rearrangements, protein structural changes, etc.). Following additional minimal allele frequency

295 (MAF) filtering, in the Indica dataset (MAF 5\%, 2,027,294 SNPs), there were 11,906 "High impact"

296 SNPs in 7,396 genes and the Japonica dataset (MAF 5\%, 1,125,716 SNPs), there were 6,240 "High

297 impact" SNPs in 4,439 genes of which 2,818 were present in both Indica and Japonica.

299 None of the 453 SNPs with a significant association was annotated as resulting in protein changes

300 ("High impact" SNPs). However, "High impact" effects were identified in other SNPs within the

301 QTL. Among the total 1,730 genes in the 21 QTLs, we annotated 309 genes with "High impact" SNPs

302 in the Indica subpanel, 248 genes with "High impact" SNPs in the Japonica subpanel, including 137

303 "High impact" SNPs common between the two sets. 129 of the 309 genes and 94 of the 248 genes had 
304 functional annotations in PhytoMine [21], but no functional overrepresentation was found for these

305 sets of genes. In addition, we looked for overlaps with the QTL in five published Vietnamese studies

306 [9-13], which used 25,971 SNPs in 182 samples (164 in common). We found that 2_GL and 6_GS

307 overlapped with QTL for panicle morphological traits [10]; 2_GL overlapped with QTL9 for

308 secondary branch number, and spikelet number (SBN and SpN), and 2_GS overlapped with QTL12

309 for secondary branch average length (SBL). 4_GW_jap overlapped with "q1" for longest leaf length

310 (LLGHT) [9].

\section{Differential selection between subpopulations}

313 To identify genomic regions which have been selected during the breeding of rice within Vietnam, we

314 searched for genomic regions with distorted patterns of allele frequency that cannot be explained by

315 random drift using XP-CLR [22]. Selected regions between pairs of either Indica or Japonica

316 subpopulations were identified first. These regions were subsequently merged into a final set of

317 selected regions for each subpopulation when regions were found to be selected against at least three

318 subpopulations for Indica (Additional file 1: Table S10, Additional file 5: Figure S19) or at least two

319 subpopulations for Japonica (Additional file 1: Table S10, Additional file 5: Figure S20). Here, we

320 describe the procedure in more detail for the comparison of the I5 subpopulation to the other four

321 Indica subpopulations: I5 vs I1 yielded 207 regions with a mean length of $267 \mathrm{kbp}$ (14.8\% of the

322 genome); I5 vs I2 yielded 120 regions with a mean length of $204 \mathrm{kbp}$ (6.57\% of the genome); I5 vs I3

323 yielded 14 regions with a mean length of $162 \mathrm{kbp}(0.61 \%$ of the genome); I5 vs I4 yielded 122

324 regions with a mean length of $122 \mathrm{kbp}(6.02 \%$ of the genome). Regions selected against three or more

325 subpopulations were merged to give 52 selected regions in I5, these had a mean length of $584 \mathrm{kbp}$

326 covering $30 \mathrm{Mbp}$, which represented $8.13 \%$ of the rice genome and contained 4,576 genes. The

327 selected regions for all of the subpopulations are plotted along each of the chromosomes in Fig. 6a

328 and $6 \mathrm{~b}$ for the Indica and Japonica subtypes, respectively. The list of genes selected in each

329 subpopulation is available in Additional file 1: Table S11. The list of genes selected for each of the 52

330 regions in subpopulation I5 is available in Additional file 1: Table S12. Functional enrichment was

331 found within 34 of the 52 regions (Additional file 1: Table S13). The mean whole-genome XP-CLR 
332 scores for each comparison are summarised in Fig. 6c and 6d. The I5 subpopulation showed the

333 highest XP-CLR score, with an average of 41.4. The I3, J4, J2 and I4 had XP-CLR scores from 28 to

334 20. The J1 and I1 subpopulations had the lowest XP-CLR scores of 10.5 and 7.6, respectively.

335 Overall, a greater number of selected regions were identified in the Indica than in the Japonica

336 subtypes. These selected regions were distributed throughout the genome, whereas in the Japonica

337 subtypes fewer regions were observed concentrated in specific regions of the genome. To gain

338 insights into which traits and underlying genes have been selected in these regions, we looked for the

339 overlap of selected regions with the 21 QTLs (Table 1). Also, we looked for overlaps with the QTLs

340 identified in the five Vietnamese rice studies relating to root [9] and panicle morphological traits [10],

341 tolerance to water deficit [11], leaf mass traits [12] and growth mediated by Jasmonate [13] (Fig. 7.

342 Additional file 1: Table S14 and Table S15).

344 To gain further information on the uniqueness of these regions selected in I5, we calculated the $\mathrm{F}_{\mathrm{ST}}$

345 per SNP between the 43 samples in the I5 subpopulation and the 190 samples in the I2, I3 and I4

346 subpopulations. The mean $\mathrm{F}_{\mathrm{ST}}$ per gene for the 4,576 genes selected in I5 is listed in Additional file 1:

347 Table $\mathrm{S} 16$ ) and the mean $\mathrm{F}_{\text {ST }}$ per selected region is shown in Table 2. The 1,983,066 heterozygous

348 SNPs in subpopulations I2, I3, I4 and I5 had a mean $\mathrm{F}_{\mathrm{ST}}$ of 0.185 , and this increased to 0.305 for the

349 subset of 177,874 SNPs found within the I5 selected regions. Twenty-one genes with a putative role

350 in salt tolerance in rice [23] fell within the regions selected in the I5 subpopulation (Additional file

351 1:Table S17). Fifty-six candidate genes were selected using the following criteria; $F_{\text {ST }}$ over 0.5 for the

352 whole selected region or for functionally enriched genes within regions, presence of "High impact"

353 SNPs, and presence of candidate genes from overlapping QTL (Table 3). Allele plots for the "High

354 impact" within genes are shown in Additional file 6: Figure S21.

\section{Discussion}


359 Whole-genome sequencing of 616 Vietnamese rice accessions, predominantly landraces, plus 56

360 Vietnamese genotypes previously sequenced by the 3K RGP, provides us with a diversity panel to

361 clarify the structure of rice subpopulations in Vietnam. Here, we describe five Indica subpopulations

362 and four Japonica subpopulations using phenotypic measurements from this study, passport

363 information available from the Vietnamese National Genebank (PRC), and the agronomic and

364 geographical annotations from Phung et al. [8]. In general terms, our population structure within

365 Vietnam agreed with the previous study, which used a smaller number of markers and 182 samples

366 and is approximately a third of our diversity panel [8]. Subpopulation I1 is the most phenotypically

367 distinct of the Indica subpopulations and shows typical phenotypes of 'elite' varieties, such as short

368 height, strong culm strength, long slender grains and a short growth-duration (less than 120 days from

369 sowing to harvest). I1 accessions are grown throughout Vietnam in irrigated ecosystems but

370 predominantly in the Mekong River Delta in the south of the country. Subpopulation I2 is mainly

371 composed of long growth-duration (over 140 days), tall varieties grown in the rainfed lowland and

372 irrigated ecosystems of the Mekong River Delta with a broad diversity of grain shapes. The remaining

373 three Indica subpopulations are intermediate between I1 and I2 for growth-duration, height and culm

374 strength, have a broad diversity of grain shapes, and are not grown in the Mekong River Delta.

375 Subpopulation I3 has the highest proportion of upland varieties but also includes some lowland

376 varieties from the "South Central Coast" region many of which were classified as an independent

377 subpopulation (I6) by Phung et al. [8]. Subpopulation I4 is mainly grown in the rainfed lowland and

378 irrigated ecosystems of the Red River Delta. Subpopulation I5 is grown in a range of ecosystems but

379 concentrated around the North Central Coast and Red River Delta regions, but excluding the

380 Northwest region suggesting that it is the main lowland subpopulation. The J1 and J3 subpopulations

381 are closely related upland varieties and the $\mathrm{J} 2$ and $\mathrm{J} 4$ subpopulations are closely related lowland

382 varieties. Subpopulation J1 is mostly composed of medium growth-duration upland varieties from the

383 mountainous regions in the North of Vietnam, with long large grains typical of upland varieties.

384 Subpopulation $\mathrm{J} 2$ is grown throughout Vietnam in a range of ecosystems but has consistently short

385 grains. Subpopulation J3 is mainly grown in the "South Central Coast" region and has long large 
386 grains. Subpopulation J4 is primarily grown in the Red River Delta region in lowland and mangrove

387 ecosystems and has short grains.

389 The drought tolerance of these subpopulations can be inferred from the root traits measured by Phung

et al. [9]The J1 and J3 upland subpopulations have deeper and thicker roots than the thinner shallower roots in the $\mathrm{J} 2$ and $\mathrm{J} 4$ subpopulations, which are grown in irrigated and mangrove ecosystems [9].

This suggests that the $\mathrm{J} 1$ and $\mathrm{J} 3$ subpopulations, which are grown mainly in rainfed upland regions,

393 would be more drought tolerant than the others. Similarly, the I3 subpopulation has the deepest and

thickest roots. It would, therefore, be more drought tolerant than the I1 and to a lesser extent the I5

subpopulation, which has the thinnest, shallowest root systems.

\section{A comprehensive analysis of the available 3,635 Asian cultivated rice genomes}

398 The comprehensive analysis of the combined 3,635 Asian cultivated rice genomes obtained by joining

399 our diversity panel with the full 3K RGP dataset resulted in a similar assignation to the previous $3 \mathrm{~K}$

400 RGP analysis in $84 \%$ of the cases. The largest differences were that the 3K RGP split the cA and XI-

4012 subpopulations, while our analysis split the GJ-tmp and rearranged the two XI-3B subpopulations

402 into Ind-3.2, Ind-3.3 and Ind-3.4. The single temperate subpopulation (GJ-tmp) from the 3K RGP is

403 further split in our study between the Jap-tmp.1 and Jap-tmp.2 subpopulations, with $88 \%$ of the

404 samples in Jap-tmp.2 coming from Vietnam and forming the J2 subpopulation. These differences are

405 likely due to changes in the distribution of genetic variants in subpopulations expanded within

406 Vietnam.

408 Vietnamese rice subpopulations in the context of the 3K RGP Asian cultivated rice

410 The Indica I1 subpopulation, which contains a high proportion of elite varieties, clustered with the

411 X1-1B1 subpopulation of modern varieties. The Southeast Asian native subpopulations (XI-3B1 and

412 XI-3B2) clustered with the I2 and I4 subpopulations, respectively. I3 appeared to include both XI-3B1

413 and XI-3B2 accessions. The subpopulations from East and South Asia (XI-1A, XI-2A, XI-2B, XI-3A) 
414 had no representatives from Vietnam and fell outside of the Vietnamese subpopulation clusters, as

415 expected. Our four Vietnamese Japonica subpopulations relate to the tropical (J1), subtropical (J3)

416 and temperate (J2 and J4) Japonica subpopulations from the 3K RGP according to their latitudinal

417 origin from South to North Vietnam, respectively.

418

419 The most exciting subpopulation is I5. When all 3,635 samples were considered, the subpopulation

420 XI-3.4 included half of the I3, all but one of I4 and all I5 Vietnamese accessions, as well as half of the

421 Southeast Asian native XI-3B2 genotypes from the 3K RGP. The remaining XI-3B2 were classified

422 as Indica admix (Ind-adm). However, when only the Vietnamese samples were considered in the

423 analysis, I5 clustered distinctly away from I3 and I4 subpopulations (Fig. 2A) and included five

424 accessions from the 3K RGP, which had very low shared ancestry (admixture components) with other

425 3K RGP samples. Notably, Vietnamese landrace IRIS 313-11384 (IRGC 127275) had no shared

426 ancestry with any other Vietnamese 3K RGP genotypes. Remarkably, a recent study on genomic

427 signals of admixture and alien introgression in a core collection of 948 accessions representative of

428 the earlier Asian Rice Landraces [24] included IRIS 313-10751 (IRGC 127577) and IRIS_313-11383

429 (IRGC 127274) from the I5 subpopulation.

\section{Genome-wide association analysis in Vietnamese rice landraces highlight 21 QTL}

432 We have also extended upon five published GWAS [9-13], which focussed on specific traits but used

433 a smaller number of markers and a third of the samples from the Vietnamese dataset. We took a

434 similar approach of carrying out the analysis on both the full panel and the Indica and Japonica

435 subpanels. Showing the QTL for the various traits altogether in Fig. 7 has highlighted some

436 interesting overlaps. Notably, the overlap of QTL for panicle morphology with our QTL for grain size

437 (2_GL and 6_GS). These previous studies found QTL in the full panel and in the Indica subpanel, but

438 not in the Japonica subpanel. However, we found QTL for grain size that were only present in the

439 Japonica subpanel, and all the QTL found in the Indica subpanel were also found in the full panel.

440 These differences probably reflect our larger dataset. Comparing our results with the GWAS results

441 from the 3K RGP (https://snp-seek.irri.org/) [25, 26], the QTL 5_GS on chromosome 3 is in the same 
442 region as a marker associated with grain length, and the QTL 10_GS on chromosome 5 is in the same

443 region as a marker associated with both grain width and grain length. Underlying these two QTL,

444 there are genes that have a putative role in the control of grain size in rice [27], namely GS3

445 (Os03g0407400) in 5_GS and GSE5 (LOC_Os05g09520, Os05g0187500) in 10_GS. We also looked

446 for genes with "High impact” SNPs in QTL, relevant candidates include bip130 [28]

447 (LOC_Os05g02260, Os05g0113500) with a stop gain mutation underlying the QTL 9_PL for panicle

448 length and OsSPX-MFS3 (LOC_Os06g03860, Os06g0129400) [29] with a splice acceptor variant at

449 the end of an intron underlying the QTL 11_GL for grain length.

\section{Breeding signatures between subpopulations focussing on the Indica I5 subpopulation}

452 Unravelling the genomic differences between these described subpopulations, which are adapted to

453 multiple environmental conditions and regional food preferences in Vietnam, provides an insight into

454 the genomic regions associated with these adaptations. Selection causes detectable changes in the

455 allele frequencies of the selected sites and their flanking regions. By jointly modelling loci allele

456 frequency differentiation and frequency under neutrality and selection, the cross-population

457 composite likelihood ratio test (XP-CLR) can detect selective sweeps [22]. These distorted patterns in

458 allele frequency in contiguous SNP sites would have occurred too quickly (speed of change is

459 assessed over expanding windows based on the length of the affected region) to be explained by

460 random drift. XP-CLR has been used to identify regions of selection associated with domestication

461 and improvement in a wide range of crops such as apple [30], soybean [31], cucumber [32] and wheat

462 [33]. In rice, XP-CLR was used more specifically to compare upland and irrigated rice accessions

$463[18]$ and to compare Indica semi-dwarf modern bred varieties (IndII) with taller Chinese landraces

464 (IndI) [17] and revealed 200 regions spanning $7.8 \%$ of the genome, which might reflect their

465 adaptation to local agricultural practices and farming conditions. We have used a similar approach to

466 identify selected regions in all of the subpopulations, showing the strongest selection in the I5

467 subpopulation with fewer regions being selected overall in the Japonica subpopulations. We have

468 examined the 52 selected regions in the I5 subpopulation in more detail. Specifically, we looked for

469 overlaps with the selected genes identified in the above two studies (Lyu et al. [18] and Xie et al. 
470 [17]) using XP-CLR in rice. Moreover, to give us indications of the possible traits selected in these

471 regions, we carried out a functional annotation of the regions and looked for overlaps with QTL.

473 Diversity is reduced when regions are under selection, but the observed diversity depends on many

474 factors, including how long ago the selection occurred and the type of alleles selected alongside. This

475 is referred to as the hitchhiking effect [34]. The fixation index $\left(\mathrm{F}_{\mathrm{ST}}\right)$ is a measure of population

476 differentiation due to genetic structure. Both measurements vary highly along the genome but can

477 provide additional information about the selected regions identified using XP-CLR. In this study, we

478 calculated $\mathrm{F}_{\mathrm{ST}}$ by comparing the I5 accessions to accessions in subpopulations I2, I3 and I4. We did

479 not include the accessions in the elite I1 subpopulation, as we are specifically interested in genes that

480 have been selected during the breeding of landraces within Vietnam.

Lyu et al. [18] identified 56 Indica-specific genes in selected regions which may account for the

483 phenotypic and physiological differences between upland and irrigated rice. Thirty-one of these genes on chromosome 3 lie within regions also selected in the I4 and I5 subpopulations (I5_23, I4_24), the gene with the highest $\mathrm{F}_{\mathrm{ST}}$ of 0.67 is ptr8 (LOC_Os03g51050, Os03g0719900), which encodes a peptide transporter [35]. Xie et al. [17] identified 2,125 and 2,098 coding genes in regions selected in the Chinese landraces (IndI) and modern-bred (IndII) subpopulations, respectively. Comparing with the genes in selected regions in the I5 subpopulation evidenced an overlap of 131 genes with the 2,125 genes selected in the IndI subpopulation and an overlap of 235 genes with the 2,098 genes selected in the IndII subpopulation. This includes nine genes on chromosome 3, which were selected in all three subpopulations (7 genes in I5_22 and two genes in I5_23).

493 Of the 52 regions selected in the $\mathrm{I} 5$ subpopulation, the six with a mean $\mathrm{F}_{\mathrm{ST}}$ over 0.5 were studied in more detail to highlight potential candidate genes. Notably, we identified the following genes in region I5_35; the transcription factor WOX11 involved in crown root development [36] and OsCam1,

496 OsbZIP63, and OsSDR, which have putative roles in defence [37]. Further genes of interest are 497 OSAAP6, a regulator of grain protein content [39] in region I5_5, OsBSK3 [38] and WSL5 [39] which 
498 play a role in growth in region I5_29, OsABP which is upregulated in response to multiple abiotic

499 stress treatments [40] falls within region I5_33 and OsSFR6, a cold-responsive gene [41] in region

500 I5_47. Two of the genes contained "high impact" mutations, OsFBX398, an F-box gene with a

501 potential role in both abiotic and biotic stresses [42, 43] in region I5_49 and bip130 [28] in region

502 I5_30 which regulates abscisic acid-induced antioxidant defence and fall within our QTL for panicle

503 length (9_PL).

504

505 We have shown that subpopulation I5 constitutes an untapped resource of cultivated rice diversity.

506 The analysis restricted to Vietnamese accessions allowed us to observe differences among the

507 accessions within the country. Although 38 accessions (including two genotypes from the same

508 accession in our study) are deposited in the PRC in Hanoi, and the remaining five accessions are

509 available from the $3 \mathrm{~K}$ RGP, there is limited information from the passport and phenotypic data to be

510 able to understand the distinctiveness of this subpopulation fully. Further analysis of this

511 subpopulation should encompass 'Indica specific genes' which may have been overlooked in our

512 study as we used a Japonica reference. Phung et al. [8] described subpopulation I5 as "medium

513 growth-duration accessions from various ecosystems of the North and South Central Coast regions,

514 with rather small and non-glutinous grains". Our I5 accessions are predominantly from the Red River

515 Delta and contiguous coastal departments, the "North Central Coast" and "Northwest" administrative

516 regions, but remarkably excluding the higher altitude Northwest region in the North, the more upper

517 "Central Highlands", as well as the whole Mekong River Delta in the south. This suggests that I5

518 accessions are common traditional low yielding lowland varieties with specific environmental or

519 culinary values.

521 Vietnam is currently experiencing increasing variability in the local climate due to global changes and

522 the growing severity of the El Nino-Southern Oscillation phenomenon, creating notable inter-annual

523 variations in precipitation ranging from severe drought to large-scale floods [5]. The Mekong River

524 Delta region is an essential region for rice production globally, but the adverse effects of salinisation

525 have damaged rice production in recent decades [6]. In addition, long-term trends in rainfall and 
526 temperature patterns have been identified in areas with a high proportion of agricultural land.

527 Genomic studies on the locally adapted varieties and subpopulations will provide a potential source of

528 novel alleles which can be exploited in rice breeding programs, such as the new generation of

529 sustainable 'Green Super Rice' which are designed to have lower inputs, enhanced nutritional content

530 and suitability for growing on marginal lands [14].

\section{Conclusions}

534 In this study, we generated a large genome-variation dataset for rice by sequencing 616 accessions

535 from Vietnam and supplementing these with the data obtained for the 3K RGP. Using this resource,

536 we incorporated the Vietnamese rice diversity within the population structure of the Asian cultivated

537 rice. We also identified breeding signatures of selection for the four Japonica and five Indica

538 subpopulations described in this study. The I5 Vietnamese Indica subpopulation showed the highest

539 level of selection, and the elite I1 Indica subpopulation showed the lowest. Overall selection was

540 higher in the Indica subtypes than the Japonica subtypes reflecting the higher diversity of the Indica

541 subtypes. In addition, a GWAS analysis yielded the strongest associations for grain characteristics and

542 weaker associations for a range of characteristics such as panicle length, heading date and leaf width.

543 We used these associations together with published QTLs obtained using a subset of our accessions to

544 give us an insight into traits underlying the regions identified as being under breeding selection.

545 Comparing the Vietnamese subpopulations to the fifteen Asian rice subpopulations identified from the

546 3K RGP highlighted the I5 subpopulation as a potential source of novel variation as it forms a well-

547 separated cluster. Subpopulation I5 originates from lowland areas such as the Red River Delta and

548 adjacent regions. For the range of phenotypes measured in this study, the I5 subpopulation did not

549 differ phenotypically from the other landraces, which have undergone breeding selection within

550 Vietnam. However, compared to the 'elite' I1 subpopulation, I5 accessions have shorter grains, take

551 longer to flower, having lower culm strength, longer culms and leaves. We carried out a

552 comprehensive annotation of the 52 regions selected in I5, which represented $8.1 \%$ of the genome and 
bioRxiv preprint doi: https://doi.org/10.1101/2020.07.07.191981; this version posted July 8, 2020. The copyright holder for this preprint (which was not certified by peer review) is the author/funder, who has granted bioRxiv a license to display the preprint in perpetuity. It is made available under aCC-BY-ND 4.0 International license.

553 contained 4,576 genes. Candidate genes were identified within these regions as potential breeding

554 targets. 


\section{Materials and Methods}

\section{Sequencing of $\mathbf{6 1 6}$ accessions from Vietnam}

558 We sequenced a total of 616 rice accessions, 612 accessions from Vietnam and three reference

559 accessions, Nipponbare, a temperate Japonica; Azucena, a tropical Japonica; and IR64, an Indica (2

560 samples). 511 accessions are available from the Vietnamese National Genebank (PRC) at

561 http://csdl.prc.org.vn (Additional file 1: Table S1). All Vietnamese native rice landraces were grown

562 at Dai Dong Experimental Farm (Dai Dong commune, Thach That district, Hanoi, Vietnam) in 2015.

563 The healthy seeds generated from one mature spikelet of the individual plant in each landrace were

564 harvested and dried separately. After that, the selected seeds (35-40 seeds/landrace) were incubated

565 and sown for two weeks to collect leaf samples (30g/sample) for genomic DNA extraction.

566 Total genomic DNA extraction of each rice landrace was made from young leaf tissue using the

567 Qiagen DNeasy kit (Qiagen, Germany). DNA concentration and purity of the samples were measured

568 by the UV-VIS NanoDrop ND-2000 spectrophotometer (Thermo Fisher Scientific) at OD 260/280 nm

569 and OD 260/230 nm wavelengths.

571 Sequencing was performed by Genomic Services at the Earlham Institute (Norwich, UK). Around

$5721 \mu \mathrm{g}$ of genomic DNA from each sample was used to construct a sequencing library. For the 36 high

573 coverage samples (prefix: SAM) the Illumina TruSeq DNA protocol was followed, and the samples

574 were sequenced on the HiSeq 2000 for 100 cycles. For the low coverage samples (prefix: LIB),

575 genomic DNA was sheared to 500bp using the Covaris S2 Sonicator (Covaris and Life technologies),

576 and samples were processed using the KAPA high throughout Library Prep Kit (Kapa Biosystems,

577 MA, USA). The ends of the DNA were repaired for the ligation of barcoded adapters. The resulting

578 libraries were quality checked, pooled, and quantified by qPCR. The libraries were sequenced on a

579 HiSeq 2500 instrument following the manufacturer's instructions.

\section{Phenotyping}


582 Phenotyping experiments were conducted at the Thach That Experimental Farm of AGI in 2014 and

5832015 (Dai Dong commune, Thach That district, Hanoi, Vietnam). The seeds of each rice landrace

584 were incubated in an oven at $45^{\circ} \mathrm{C}$ for five days to break the seed dormancy. All rice seeds were

585 soaked in tap water for two days and incubated at $35-40^{\circ} \mathrm{C}$ for four days for germinating. The fully

586 germinated seeds of each rice landrace were directly sown in the paddy field plot $\left(1.5 \mathrm{~m}^{2}\right.$ in the area).

587 After 15 days of sowing, 24 seedlings of each landrace were carefully transplanted by hand in field

588 plots $\left(2 \times 4 \mathrm{~m}^{2}\right)$. The fertiliser and pesticide applications were performed following the conventional

589 methods of rice cultivation in Vietnam. The phenotypic and agronomic characteristics were carried

590 out following the method of IRRI [44].

591

592 In addition, phenotypic data were available for eleven of the traits in 38 of the 56 genotypes sourced

593 from the 3K-RGP dataset. These eleven traits were included in our analysis because we did not

594 observe a significant difference ( $\mathrm{p}$-value > 0.07) between our dataset and the $3 \mathrm{~K}-\mathrm{RGP}$ dataset for the

595 I2 subpopulation (Additional file 1: Table S5).

596

597 Merging the SNP called in the sequenced materials and the complete 3K RGP dataset

598 Raw sequencing reads were mapped to the Nipponbare reference genome Os-Nipponbare-Reference-

599 IRGSP-1.0 (IRGSP-1.0), using BWA-MEM with default parameters except for “-M -t 8”. Alignments

600 were compressed, sorted and merged using samtools. Picard tools were then used to mark optical and

601 PCR duplicates and add read group information. We used freebayes v1.1.0 for variant calling using

602 default parameters. A total of 21.2 M variants were identified of which 16.4 M were SNPs, and 4.8 M

603 were indels. The resulting VCF file was then filtered for biallelic SNPs with a minimum SNP quality

604 of 30, resulting in 16.0 M variants. PLINK v1.9 was used to convert the VCF into a PLINK BED

605 format. These variants were then combined with the 3K-RGP 29 M biallelic SNPs dataset v1.0 by

606 downloading the PLINK BED files from the "SNP-seek" database (https://snp-seek.irri.org) excluding

607 variants on scaffolds and 26,553 SNPs that were flagged as triallelic upon merging, resulting in 36.9

608 M SNPs. The SNPs present in both datasets were then extracted and filtered using an identical

609 approach to Wang et al. [15], resulting in 5.9 M SNPs. For that, PLINK v1.9 “--hardy" [45] was used 
610 to obtain observed and expected heterozygosity for 100,000 SNPs. We removed SNPs in which

611 heterozygosity exceeds Hardy-Weinberg expectation for a partially inbred species, with inbreeding

612 coefficient (F) estimated as the median value of "1-Hobs/Hexp", in which Hobs and Hexp are the

613 observed and expected heterozygosity for SNPs where "Hobs/Hexp <1" and the minor allele

614 frequency is $>5 \%$ and using the cut-off value of 0.479508 for the entire 3,622 samples dataset. A

615 further filtered set of 3.4 M SNPs was obtained by removing SNPs with >20\% missing calls and MAF

$616<1 \%$. Finally, a core set of 361,279 SNPs was obtained with PLINK by LD pruning SNPs with a

617 window size of 10 SNPs, window step of one SNP and $\mathrm{r} 2$ threshold of 0.8 , followed by another round

618 of LD pruning with a window size of 50 SNPs, window step of one SNP and $\mathrm{r} 2$ threshold of 0.8 .

619 Samples with more than 50\% missing data in this core set were then removed, resulting in dropping

620 seven newly sequenced samples and one genotype from the 3K-RGP dataset.

\section{Population structure of the combined 3,635 samples}

623 The population structure was analysed using the ADMIXTURE software [46] on the SNP set obtained 624 in the previous section. First, ADMIXTURE was run from $\mathrm{K}=5$ to $\mathrm{K}=15$ in order to compare it with

625 the analysis from IRRI $[15,16]$. For each K, ADMIXTURE was then run 50 times with varying

626 random seeds. Each matrix was then annotated using the subpopulation assignment from the 3K-RGP

627 nine subpopulations. Then, up to 10 Q-matrices belonging to the largest cluster were aligned using

628 CLUMPP software [47], these were averaged to produce the final matrix of admixture proportions.

629 Finally, the group membership for each sample was defined by applying a threshold of $\geq 0.65$ to this

630 matrix. Samples with admixture components $<0.65$ were classified as follows. If the sum of

631 components for subpopulations within the major groups (Ind and Jap) was $\geq 0.65$, the samples were

632 classified as Ind-adm or Jap-adm, respectively, and the remaining samples were deemed admixed

633 (admix).

634 Multi-dimensional scaling analysis was performed using the 'cmdscale' function in R, using a

635 distance matrix obtained in $\mathrm{R}$ using the Dist function from the amap package [48]. The resulting file

636 was then passed to Curlywhirly [49] and rgl v0.100.19 (https://r-forge.r-project.org/projects/rgl/) for

637 visualisation. 
639 Recalling the diversity panel with $\mathbf{7 2 3}$ samples

640 The 616 rice samples were mapped to the Japonica Nipponbare (IRGSP-1.0) reference with BWA-

641 MEM using default parameters, duplicate reads were removed with Picard tools (v1.128) and the bam

642 files were merged using SAMtools v1.5 [50]. Variant calling was completed again on the merged bam

643 file with FreeBayes v1.0.2 [51] separately for each of the 12 chromosomes, but using the option “--

644 min-coverage 10". Over 6.3 M bi-allelic SNPs with a minimum allele count of $\geq 3$ and quality value

645 above 30 and missing in $<50 \%$ of samples were obtained with VCFtools v0.1.13 [52]. BAM

646 alignment files to the Nipponbare IRGSP 1.0 reference genome were downloaded from http://snp-

647 seek.irri.org/ $[25,26]$ for 107 selected samples. Alignment statistics are included in Additional file 1:

648 Table S18. These BAM files were merged and variant calling was similarly completed using

649 FreeBayes v1.0.2 [51] separately for each of the 12 chromosomes using the option --min-coverage 10,

650 and filtered with VCFtools v0.1.13 as before to obtain $6.8 \mathrm{M}$ bi-allelic SNPs with a minimum allele

651 count of $\geq 3$ and quality value above 30 and missing in $<50 \%$ of samples. The two sets of $6.3 \mathrm{M}$ and

652 6.8 M SNPs were merged using BCFtools v1.3.1 isec to obtain 4.4 M SNPs which were present in

653 both sets and in at least 70\% of samples. These 4.4 M SNPs were then filtered to remove positions

654 which fell outside the expected level of heterozygosity for this dataset, as previously indicated. The

655 resulting estimate of $\mathrm{F}$ for the 723 samples was 0.882 , so a SNP whose heterozygosity is $>5 \mathrm{x}$ higher

656 than the most likely value for a given frequency and the dataset's inbreeding rate will be deemed as

657 having an excessive number of heterozygotes. The cut-off value was 0.591 , which resulted in $3.8 \mathrm{M}$

658 SNPs passing this filter, a scatter plot indicating the SNPs which were kept and removed is shown in

659 Additional file 2: Figure S15. Missing data was imputed in this latest dataset using Beagle v4.1 with

660 default parameters [53]. A comparison using PCA, between the imputed and non-imputed SNP sets

661 showed that imputation did not change the clustering of these 723 samples (Additional file 2: Figure

662 S16). The 3.8M SNPs were subsequently filtered for minimum allele frequency (MAF), linkage

663 disequilibrium (LD pruning or filtering), and distance between polymorphisms (thinning) in different 
664 subsets of samples to obtain fourteen sets of SNPs that ranged from 59K to 3.8M SNPs, which were

665 appropriate for the various downstream analysis described below (Additional file 1: Table S19).

667 Population structure and diversity analysis for the panel of 672 Vietnamese samples

668 SNP sets were filtered for MAF 5\%, followed by LD filtering using PLINK --indep-pairwise 5010

669 0.2, with further thinning if required. We ran STRUCTURE [19] v2.3.5 using the default admixture

670 model parameters; each run consisted of 10,000 burn-in iterations followed by 50,000 data collection

671 iterations. STRUCTURE was run using K=2 for the 616 samples using SNP set 1 (163,393 SNPs).

672 Samples with admixture components $<0.75$ were classified as admixed, and the remaining samples

673 were classified as Indica or Japonica. STRUCTURE was run varying the assumed number of genetic

674 groups (K) from 3 to 10 with three runs per $\mathrm{K}$ value for the 672 Vietnamese samples (SNP set 9 -

67580,000 SNPs); from 1 to 8 with ten runs per K value for the 426 Indica subtypes from Vietnam (SNP

676 set 10 - 108,420 SNPs) and the 211 Japonica subtypes from Vietnam (SNP set $11-59,815$ SNPs).

677 The output files were visualised using the R package POPHELPER v.2.2.7 [54] including the

678 calculation of the number of clusters (K) using the Evanno method [20, 55]. Using the combined-

679 merged clumpp output from POPHELPER, Indica $(\mathrm{K}=5)$ and Japonica $(\mathrm{K}=4)$ samples were classified

680 into Indica I1 to I5 and Japonica J1 to J4 subpopulations using a threshold of >= 0.6, with the

681 remaining samples being classified as mixed (Im and Jm). The principal component analysis (PCA)

682 was performed using the R package SNPRelate v1.16.0 [55] using method = 'biallelic'. Nucleotide

683 Diversity $(\pi)$ was measured for each of the subpopulations with VCFtools v0.1.13 using 100-kbp

684 windows and a step size of $10 \mathrm{kbp}$.

\section{Determining the effect of SNPs}

687 The effects of all bi-allelic SNPs (low, medium and high effects) on the genome were determined

688 based on the pre-built release 7.0 annotation from the Rice Genome Annotation Project

689 (http://rice.plantbiology. msu.edu/) using SnpEff [56] release 4.3, with default parameters. The

690 complete set of 3,750,621 SNPs (SNP set 2) which contained on average one variant every 99 bases 
691 was annotated. Using sequence ontology terms, the effect of each SNP was classified as described by

692 SnpEff. A summary of the SNP effect analysis is available in Additional file 1: Table S20.

693

694 Genome-wide association analysis

695 Three independent analyses were conducted using the full panel (672 samples, 361,191 SNPs), the

696 Indica subpanel (426 samples, 334,935 SNPs) and the Japonica subpanel (211 samples, 122,881

697 SNPs), SNP sets 12, 13 and 14 respectively (Additional file 1: Table S19). The GWAS analysis was

698 performed by employing the R package Genome Association and Prediction Integrated Tool (GAPIT)

699 version $3.0[57,58]$. The covariate matrix was generated in STRUCTURE. We used the combined-

700 merged output from POPHELPER for the full panel $(\mathrm{K}=8)$, the Indica subpanel $(\mathrm{K}=5)$ and the

701 Japonica subpanel $(\mathrm{K}=4)$. The covariate matrix and the kinship calculated in GAPIT were included in

702 the GWAS model to control for false positives. The SUPER (Settlement of MLM Under

703 Progressively Exclusive Relationship [59] method integrated into GAPIT, designed to increase the

704 statistical power, was used to perform the association mapping analysis. The SUPER method was

705 implemented in GAPIT by setting the parameter of "sangwich.top" and "sangwich.bottom" to CMLM

706 and SUPER, respectively. A quantile-quantile (Q-Q) plot was used to check if the model was

707 correctly accounting for both confounding variables. Associations held by peaks with $-\log _{10}$ (p-value)

$708 \geq 8.0$ were used to declare the significant associations. The Genes lying within the QTL regions were

709 extracted and subjected to enrichment analysis using PhytoMine implemented within Phytozome [21]

710 https://phytozome.jgi.doe.gov/ for Gene Ontology, Protein Domain and Pathway enrichment using a

711 max p-value of 0.05 with Bonferroni correction.

712

\section{Identification of selective sweeps using XP-CLR}

714 Selective sweeps across the genome were identified using XP-CLR, a method based on modelling the

715 likelihood of multilocus allele frequency differentiation between two populations. An updated version

716 ( https://github.com/hardingnj/xpclr) of the code described by Chen et al. [22] was used to scan for

717 regions of selection. We used 100-kbp sliding windows with a step size $10 \mathrm{kbp}$ and the default of no

718 more than 200 SNPs per window. XP-CLR was run between the five Indica subpopulations and the 
719 four Japonica subpopulations. Selected regions were extracted using the XP-CLR score for each 100-

$720 \mathrm{~kb}$ window as follows- $200 \mathrm{kbp}$ centromeric regions were removed, and the mean XP-CLR score and

72199 th percentile were calculated for comparisons between subpopulation (e.g. I5 vs I1, I2, I3, I4) and

722 the mean of these values was used to define the cut-off level for selection in that population as shown

723 in Additional file 1: Table S10. 100-kbp regions with an XP-CLR score higher than the cut-off were

724 extracted and merged using BEDTOOLS v2.26.0 [60] specifying a maximum distance between

725 regions of $100 \mathrm{kbp}$. Regions shorter than $80 \mathrm{kbp}$ were then removed to give a final set of putatively

726 selected regions for each comparison. Overlapping regions selected in comparison with at least two

727 subpopulations for Japonica or three for Indica were then merged to obtain a final set of selected

728 regions for each subpopulation. BEDTOOLS map was used for finding any overlap of selected

729 regions with QTLs. The Genes lying within the selected regions were extracted and subjected to

730 enrichment analysis as before.

\section{Calculating $\mathbf{F}_{\text {ST }}$}

733 We calculated $F_{\text {ST }}$ per SNP between the 43 samples in the I5 subpopulation and the 190 samples in

734 the I2, I3 and I4 subpopulations with VCFtools using the "weir-fst-pop" option which calculates $\mathrm{F}_{\mathrm{ST}}$

735 according to the method of Weir and Cockerham [61]. Sites which are homozygous between these

736 populations were removed, and negative values were changed to zero. The mean $\mathrm{F}_{\mathrm{ST}}$ was calculated

737 per gene and per specified region. 


\section{Acknowledgements}

740 We thank Professor Giles Oldroyd for his contributions to the conception of this project. We are

741 grateful for the support from Dr. Nelzo Ereful, and Matt Heaton during outreach activities in Vietnam,

742 and Dr. Luca Venturi, Dr. Ricardo Ramirez Gonzalez, Dr. Graham Etherington for their support

743 during summer training activities in the UK, and Dr. Chris Watkins, Dr. Helen Chapman and the

744 Genomics Pipelines team at the Earlham Institute for the sequencing support.

\section{Funding}

747 This work was supported by the Biotechnology and Biological Sciences Research Council (BBSRC)

748 through the grants BB/N013735/1 (Newton Fund) and BBS/E/T/000PR9818, and the Newton Fund

749 Institutional Links (Project 172732508), which is managed by the British Council.

751 Availability of data

752 All sequence data used in this manuscript have been deposited as study PRJEB36631 in the European

753 Nucleotide Archive.

755 Author contributions

756 TDK, KHT, AH, SD, LHH, MC and JDV designed and conceived the research. TDK, KHT, TDD,

757 NTPD, NTK, DTTH, NTD, KTD, CNP, TTT, NTT, HDT, NTT, HTG, TKN, CDT, SVL, LTN, NVG

758 and LHH performed the phenotyping and laboratory experiments. JH and BS performed the data

759 analysis with assistance from TDD, NTPD, DTTH, NTD, KTD, NTT, LTN, TDX, MC and JDV. JH,

760 BS and JDV wrote the paper. All authors read and approved the final manuscript.

761

762 Ethics approval and consent to participate

763 Not applicable.

\section{Consent for publication}

766 Not applicable. 
bioRxiv preprint doi: https://doi.org/10.1101/2020.07.07.191981; this version posted July 8, 2020. The copyright holder for this preprint (which was not certified by peer review) is the author/funder, who has granted bioRxiv a license to display the preprint in perpetuity. It is made available under aCC-BY-ND 4.0 International license.

767

\section{Competing interests}

769 The authors declare that there is no conflict of interest regarding the publication of this article.

770

771 
774 1. Nguyen Duc K, Ancev T, Randall A: Evidence of climatic change in Vietnam: Some

775 implications for agricultural production. J Environ Manage 2019, 231:524-545.

776 2. GSO-Database: General Statistic Office in Vietnam, Database. 2017.

777 3. Parker L, Bourgoin C, Martinez-Valle A, Laderach P: Vulnerability of the agricultural 778 sector to climate change: The development of a pan-tropical Climate Risk Vulnerability 779 Assessment to inform sub-national decision making. PLoS One 2019, 14:e0213641.

780 4. Son NY, BT. Sebastian LS.: Development of Climate-Related Risk Maps and Adaptation Plans (Climate Smart MAP) for Rice Production in Vietnam's Mekong River Delta. CCAFS, 2018.

783 5. Tan Yen B, Quyen NH, Duong TH, Van Kham D, Amjath-Babu TS, Sebastian L: Modeling ENSO impact on rice production in the Mekong River Delta. PLoS One 2019, 14:e0223884.

6. Tran TV, Tran DX, Myint SW, Huang CY, Pham HV, Luu TH, Vo TMT: Examining spatiotemporal salinity dynamics in the Mekong River Delta using Landsat time series germplasm provides an insight into Japonica rice differentiation. Plant Breeding 2003, 122:497-502.

8. Phung NT, Mai CD, Mournet P, Frouin J, Droc G, Ta NK, Jouannic S, Le LT, Do VN, Gantet rice accessions from Vietnam. BMC Plant Biol 2016, 16:64.

10. Ta KN, Khong NG, Ha TL, Nguyen DT, Mai DC, Hoang TG, Phung TPN, Bourrie I, Courtois B, Tran TTH, et al: A genome-wide association study using a Vietnamese 
$800 \quad$ landrace panel of rice (Oryza sativa) reveals new QTLs controlling panicle

$801 \quad$ morphological traits. BMC Plant Biol 2018, 18:282.

802 11. Hoang GT, Van Dinh L, Nguyen TT, Ta NK, Gathignol F, Mai CD, Jouannic S, Tran KD, Khuat TH, Do VN, et al: Genome-wide Association Study of a Panel of Vietnamese Rice Landraces Reveals New QTLs for Tolerance to Water Deficit During the Vegetative Phase. Rice (N Y) 2019, 12:4.

806 12. Hoang GT, Gantet P, Nguyen KH, Phung NTP, Ha LT, Nguyen TT, Lebrun M, Courtois B, landrace panel. PLoS One 2019, 14:e0219274.

813 14. Wing RA, Purugganan MD, Zhang Q: The rice genome revolution: from an ancient grain to Green Super Rice. Nat Rev Genet 2018, 19:505-517.

815 15. Wang W, Mauleon R, Hu Z, Chebotarov D, Tai S, Wu Z, Li M, Zheng T, Fuentes RR, Zhang

$816 \quad F$, et al: Genomic variation in 3,010 diverse accessions of Asian cultivated rice. Nature

$817 \quad 2018, \mathbf{5 5 7} \quad 43-49$.

818 16. Yong Zhou DC, Dave Kudrna, Victor Llaca, Seunghee Lee, Shanmugam Rajasekar, Nahed 819 Mohammed, Noor Al-Bader, Chandler Sobel-Sorenson, Praveena Parakkal, Lady Johanna Arbelaez, Natalia Franco, Nickolai Alexandrov, N. Ruaraidh Sackville Hamilton, Hei Leung,

824 17. Xie W, Wang G, Yuan M, Yao W, Lyu K, Zhao H, Yang M, Li P, Zhang X, Yuan J, et al: 
827 18. Lyu J, Li B, He W, Zhang S, Gou Z, Zhang J, Meng L, Li X, Tao D, Huang W, et al: A

828 genomic perspective on the important genetic mechanisms of upland adaptation of rice.

829 BMC Plant Biol 2014, 14:160.

830 19. J K Pritchard MS, P Donnelly: Inference of population structure using multilocus genotype data. Genetics 2000, 155:945-959.

832 20. Evanno G, Regnaut S, Goudet J: Detecting the number of clusters of individuals using the 833 software STRUCTURE: a simulation study. Mol Ecol 2005, 14:2611-2620.

834 21. Goodstein DM, Shu S, Howson R, Neupane R, Hayes RD, Fazo J, Mitros T, Dirks W, 835 Hellsten U, Putnam N, Rokhsar DS: Phytozome: a comparative platform for green plant genomics. Nucleic Acids Res 2012, 40:D1178-1186.

837 22. Chen H, Patterson N, Reich D: Population differentiation as a test for selective sweeps. $838 \quad$ Genome Res 2010, 20:393-402.

839 23. Ganie SA, Molla KA, Henry RJ, Bhat KV, Mondal TK: Advances in understanding salt $840 \quad$ tolerance in rice. Theor Appl Genet 2019, 132:851-870.

841 24. Santos JD, Chebotarov D, McNally KL, Bartholome J, Droc G, Billot C, Glaszmann JC: Fine Scale Genomic Signals of Admixture and Alien Introgression among Asian Rice

844 25. Mansueto L, Fuentes RR, Borja FN, Detras J, Abriol-Santos JM, Chebotarov D, Sanciangco M, Palis K, Copetti D, Poliakov A, et al: Rice SNP-seek database update: new SNPs, indels, and queries. Nucleic Acids Res 2017, 45:D1075-D1081.

847 26. Mansueto L, Fuentes RR, Chebotarov D, Borja FN, Detras J, Abriol-Santos JM, Palis K, 848 Poliakov A, Dubchak I, Solovyev V, et al: SNP-Seek II: A resource for allele mining and analysis of big genomic data in Oryza sativa. Current Plant Biology 2016, 7-8:16-25.

850 27. Li N, Xu R, Duan P, Li Y: Control of grain size in rice. Plant Reprod 2018, 31:237-251.

851 28. Zhou X, Ni L, Liu Y, Jiang M: Phosphorylation of bip130 by OsMPK1 regulates abscisic 852 acid-induced antioxidant defense in rice. Biochem Biophys Res Commun 2019, 514:750755. 
854 29. Wang C, Yue W, Ying Y, Wang S, Secco D, Liu Y, Whelan J, Tyerman SD, Shou H: Rice

855 SPX-Major Facility Superfamily3, a Vacuolar Phosphate Efflux Transporter, Is

856 Involved in Maintaining Phosphate Homeostasis in Rice. Plant Physiol 2015, 169:2822-

$857 \quad 2831$.

858 30. Duan N, Bai Y, Sun H, Wang N, Ma Y, Li M, Wang X, Jiao C, Legall N, Mao L, et al:

859 Genome re-sequencing reveals the history of apple and supports a two-stage model for

$860 \quad$ fruit enlargement. Nat Commun 2017, 8:249.

861 31. Zhou Z, Jiang Y, Wang Z, Gou Z, Lyu J, Li W, Yu Y, Shu L, Zhao Y, Ma Y, et al:

862 Resequencing $\mathbf{3 0 2}$ wild and cultivated accessions identifies genes related to domestication and improvement in soybean. Nat Biotechnol 2015, 33:408-414.

864 32. Qi J, Liu X, Shen D, Miao H, Xie B, Li X, Zeng P, Wang S, Shang Y, Gu X, et al: A

865 genomic variation map provides insights into the genetic basis of cucumber

866 domestication and diversity. Nat Genet 2013, 45:1510-1515.

867 33. Joukhadar R, Daetwyler HD, Gendall AR, Hayden MJ: Artificial selection causes

868 significant linkage disequilibrium among multiple unlinked genes in Australian wheat.

$869 \quad$ Evol Appl 2019, 12:1610-1625.

870 34. Pavlidis P, Alachiotis N: A survey of methods and tools to detect recent and strong $871 \quad$ positive selection. J Biol Res (Thessalon) 2017, 24:7.

872 35. Ouyang J, Cai Z, Xia K, Wang Y, Duan J, Zhang M: Identification and analysis of eight 873 peptide transporter homologs in rice. Plant Science 2010, 179:374-382.

874 36. Zhang T, Li R, Xing J, Yan L, Wang R, Zhao Y: The YUCCA-Auxin-WOX11 Module

875 Controls Crown Root Development in Rice. Front Plant Sci 2018, 9:523.

876 37. Kim EH, Kim YS, Park SH, Koo YJ, Choi YD, Chung YY, Lee IJ, Kim JK: Methyl

877 jasmonate reduces grain yield by mediating stress signals to alter spikelet development

$878 \quad$ in rice. Plant Physiol 2009, 149:1751-1760.

879 38. Zhang B, Wang X, Zhao Z, Wang R, Huang X, Zhu Y, Yuan L, Wang Y, Xu X, Burlingame

880 AL, et al: OsBRI1 Activates BR Signaling by Preventing Binding between the TPR and

881 Kinase Domains of OsBSK3 via Phosphorylation. Plant Physiol 2016, 170:1149-1161. 
882 39. Liu X, Lan J, Huang Y, Cao P, Zhou C, Ren Y, He N, Liu S, Tian Y, Nguyen T, et al: WSL5,

883 a pentatricopeptide repeat protein, is essential for chloroplast biogenesis in rice under

$884 \quad$ cold stress. J Exp Bot 2018, 69:3949-3961.

885 40. Macovei A, Vaid N, Tula S, Tuteja N: A new DEAD-box helicase ATP-binding protein

(OsABP) from rice is responsive to abiotic stress. Plant Signal Behav 2012, 7:1138-1143.

887 41. de Freitas GM, Thomas J, Liyanage R, Lay JO, Basu S, Ramegowda V, do Amaral MN,

888 Benitez LC, Bolacel Braga EJ, Pereira A: Cold tolerance response mechanisms revealed

889 through comparative analysis of gene and protein expression in multiple rice genotypes.

$890 \quad$ PLoS One 2019, 14:e0218019.

42. Jain M, Nijhawan A, Arora R, Agarwal P, Ray S, Sharma P, Kapoor S, Tyagi AK, Khurana

43. Vemanna RS, Bakade R, Bharti P, Kumar MKP, Sreeman SM, Senthil-Kumar M, Makarla U:

898 44. Institute I-IRR: Homepage of the International Rice Research Institute, Philippine 2002 (accession May 15, 2014). 2014.

900 45. Purcell S, Neale B, Todd-Brown K, Thomas L, Ferreira MA, Bender D, Maller J, Sklar P, de

46. Alexander DH, Lange K: Enhancements to the ADMIXTURE algorithm for individual

47. Jakobsson M, Rosenberg NA: CLUMPP: a cluster matching and permutation program 
910 49. Graphical applications for visualization and analysis of genotype data sets

$911 \quad$ https://ics.hutton.ac.uk/curlywhirly/. 2014.

912 50. Li H, Handsaker B, Wysoker A, Fennell T, Ruan J, Homer N, Marth G, Abecasis G, Durbin

913 R, Genome Project Data Processing S: The Sequence Alignment/Map format and

$914 \quad$ SAMtools. Bioinformatics 2009, 25:2078-2079.

915 51. Garrison E, ; Marth, G.: Haplotype-based variant detection from short-read sequencing.

9162012.

917 52. Danecek P, Auton A, Abecasis G, Albers CA, Banks E, DePristo MA, Handsaker RE, Lunter

918 G, Marth GT, Sherry ST, et al: The variant call format and VCFtools. Bioinformatics 2011,

$919 \quad 27: 2156-2158$.

920 53. Browning BL, Browning SR: Genotype Imputation with Millions of Reference Samples.

921 Am J Hum Genet 2016, 98:116-126.

922 54. Francis RM: pophelper: an R package and web app to analyse and visualize population

$923 \quad$ structure. Mol Ecol Resour 2017, 17:27-32.

924 55. Zheng X, Levine D, Shen J, Gogarten SM, Laurie C, Weir BS: A high-performance

925 computing toolset for relatedness and principal component analysis of SNP data.

926 Bioinformatics 2012, 28:3326-3328.

927 56. Cingolani P, Platts A, Wang le L, Coon M, Nguyen T, Wang L, Land SJ, Lu X, Ruden DM:

928 A program for annotating and predicting the effects of single nucleotide polymorphisms,

929 SnpEff: SNPs in the genome of Drosophila melanogaster strain w1118; iso-2; iso-3. Fly

930 (Austin) 2012, 6:80-92.

931 57. Lipka AE, Tian F, Wang Q, Peiffer J, Li M, Bradbury PJ, Gore MA, Buckler ES, Zhang Z:

932 GAPIT: genome association and prediction integrated tool. Bioinformatics 2012,

$933 \quad 28: 2397-2399$

934 58. Tang Y, Liu X, Wang J, Li M, Wang Q, Tian F, Su Z, Pan Y, Liu D, Lipka AE, et al: GAPIT

935 Version 2: An Enhanced Integrated Tool for Genomic Association and Prediction. Plant

$936 \quad$ Genome 2016, 9. 
937 59. Wang Q, Tian F, Pan Y, Buckler ES, Zhang Z: A SUPER powerful method for genome

$938 \quad$ wide association study. PLoS One 2014, 9:e107684.

939 60. Quinlan AR, Hall IM: BEDTools: a flexible suite of utilities for comparing genomic

940 features. Bioinformatics 2010, 26:841-842.

941 61. Weir BS, Cockerham CC: Estimating F-Statistics for the Analysis of Population

$942 \quad$ Structure. Evolution 1984, 38.

943 62. Peng B, Kong H, Li Y, Wang L, Zhong M, Sun L, Gao G, Zhang Q, Luo L, Wang G, et al:

944 OsAAP6 functions as an important regulator of grain protein content and nutritional

945 quality in rice. Nat Commun 2014, 5:4847.

946 63. Abbai R, Singh VK, Nachimuthu VV, Sinha P, Selvaraj R, Vipparla AK, Singh AK, Singh

947 UM, Varshney RK, Kumar A: Haplotype analysis of key genes governing grain yield and

948 quality traits across 3K RG panel reveals scope for the development of tailor-made rice

949 with enhanced genetic gains. Plant Biotechnology Journal 2019, 17:1612-1622.

950 64. Lombardo F, Kuroki M, Yao SG, Shimizu H, Ikegaya T, Kimizu M, Ohmori S, Akiyama T,

951 Hayashi $\mathrm{T}$, Yamaguchi $\mathrm{T}$, et al: The superwoman1-cleistogamy2 mutant is a novel

952 resource for gene containment in rice. Plant Biotechnol J 2017, 15:97-106.

953 65. Du H, Liu L, You L, Yang M, He Y, Li X, Xiong L: Characterization of an inositol 1,3,4-

954 trisphosphate 5/6-kinase gene that is essential for drought and salt stress responses in

$955 \quad$ rice. Plant Mol Biol 2011, 77:547-563.

956 66. Sakamoto T, Kitano H, Fujioka S: Rice ERECT LEAF 1 acts in an alternative

957 brassinosteroid signaling pathway independent of the receptor kinase OsBRI1. Plant

$958 \quad$ Signal Behav 2017, 12:e1396404.

959 67. Lira-Ruan V, Ruiz-Kubli M, Arredondo-Peter R: Expression of non-symbiotic hemoglobin

9601 and 2 genes in rice (Oryza sativa) embryonic organs. Commun Integr Biol 2011, 4:457-

$961 \quad 458$.

962 68. Kim SK, Park HY, Jang YH, Lee KC, Chung YS, Lee JH, Kim JK: OsNF-YC2 and OsNF-

963 YC4 proteins inhibit flowering under long-day conditions in rice. Planta 2016, 243:563-

964576. 
965 69. Yu M, Yau CP, Yip WK: Differentially localized rice ethylene receptors OsERS1 and

966 OsETR2 and their potential role during submergence. Plant Signal Behav 2017,

967 12:e1356532.

968 70. Yi J, Kim SR, Lee DY, Moon S, Lee YS, Jung KH, Hwang I, An G: The rice gene DEFECTIVE TAPETUM AND MEIOCYTES 1 (DTM1) is required for early tapetum development and meiosis. Plant $J$ 2012, 70:256-270.

971 71. Ying Y, Yue W, Wang S, Li S, Wang M, Zhao Y, Wang C, Mao C, Whelan J, Shou H: Two h-Type Thioredoxins Interact with the E2 Ubiquitin Conjugase PHO2 to Fine-Tune Phosphate Homeostasis in Rice. Plant Physiol 2017, 173:812-824. of OsEXO70A1 Causes Irregular Vascular Bundles and Perturbs Mineral Nutrient

977 73. Zang D, Li H, Xu H, Zhang W, Zhang Y, Shi X, Wang Y: An Arabidopsis Zinc Finger Sci 2016, 7:1272.

981 74. Sumiyoshi M, Nakamura A, Nakamura H, Hakata M, Ichikawa H, Hirochika H, Ishii T, Satoh

982 S, Iwai H: Increase in cellulose accumulation and improvement of saccharification by

983 overexpression of arabinofuranosidase in rice. PLoS One 2013, 8:e78269.

984 75. Saeng-ngam S, Takpirom W, Buaboocha T, Chadchawan S: The role of the OsCam1-1 salt

985 stress sensor in ABA accumulation and salt tolerance in rice. Journal of Plant Biology

$986 \quad 2012, \mathbf{5 5}: 198-208$.

987 76. Yuenyong W, Chinpongpanich A, Comai L, Chadchawan S, Buaboocha T: Downstream

988 components of the calmodulin signaling pathway in the rice salt stress response revealed 989 by transcriptome profiling and target identification. BMC Plant Biol 2018, 18:335.

990 77. Delteil A, Blein M, Faivre-Rampant O, Guellim A, Estevan J, Hirsch J, Bevitori R, Michel C, $991 \quad$ Morel JB: Building a mutant resource for the study of disease resistance in rice reveals 992 the pivotal role of several genes involved in defence. Mol Plant Pathol 2012, 13:72-82. 
993 78. Mukherjee S, Sengupta S, Mukherjee A, Basak P, Majumder AL: Abiotic stress regulates

994 expression of galactinol synthase genes post-transcriptionally through intron retention

995 in rice. Planta 2019, 249:891-912.

996 79. Yang S-h, Niu X-1, Luo D, Chen C-d, Yu X, Tang W, Lu B-r, Liu Y-s: Functional Characterization of an Aldehyde Dehydrogenase Homologue in Rice. Journal of Integrative Agriculture 2012, 11:1434-1444.

999 80. Park SH, Chung PJ, Juntawong P, Bailey-Serres J, Kim YS, Jung H, Bang SW, Kim YK, Do Choi Y, Kim JK: Posttranscriptional control of photosynthetic mRNA decay under stress conditions requires $3^{\prime}$ and $5^{\prime}$ untranslated regions and correlates with differential

1002 polysome association in rice. Plant Physiol 2012, 159:1111-1124.

1003 81. Chen R, Cheng Y, Han S, Van Handel B, Dong L, Li X, Xie X: Whole genome sequencing and comparative transcriptome analysis of a novel seawater adapted, salt-resistant rice cultivar - sea rice 86. BMC Genomics 2017, 18:655.

1006 82. Tanaka W, Toriba T, Hirano HY: Three TOB1-related YABBY genes are required to 
1010 Table 1: 21 QTLs identified for plant description traits in the full panel, and Indica and Japonica subpanels. Detailing for the QTL analysis;

1011 significance threshold $-\log _{10}$ ( $\mathrm{p}$ value $) \geq 8$.0; panel in which significant associations were detected, highest level of significance for all panels, the occurrence

1012 of any overlap with selected regions in the four Japonica or five Indica subpopulations, any overlap with publish QTLs for Vietnamese rice populations or for

1013 the 3K RGP.

\begin{tabular}{|c|c|c|c|c|c|c|c|c|c|c|c|c|}
\hline QTL Name & Trait & Chrom & Panel & $\begin{array}{l}\text { Segment position } \\
\text { (bp) }\end{array}$ & $\begin{array}{c}\text { Sig } \\
\text { SNPs } \\
\mathrm{nb}\end{array}$ & $\begin{array}{l}\min \\
\text { P.value }\end{array}$ & $\begin{array}{c}\text { Number of } \\
\text { genes }\end{array}$ & $\begin{array}{l}\text { FST I5 vs } \\
12,13,\left.\right|^{\wedge}\end{array}$ & $\begin{array}{l}\text { Overlap } \\
\text { with } \\
\text { selected } \\
\text { regions }\end{array}$ & $\begin{array}{l}\text { Overlap } \\
\text { with QTLs }\end{array}$ & $\begin{array}{l}\text { enrichment } \\
\text { phytozome * }\end{array}$ & $\begin{array}{l}\text { enrichment } \\
\text { phytozome } \\
*\end{array}$ \\
\hline 1_DI & Diameter_Internode & 2 & FP & $6,805,273-6,923,410$ & 3 & $\begin{array}{c}3.12 \mathrm{E}- \\
08\end{array}$ & 18 & 0.14 & 12,14 & & & \\
\hline 2_GL & Grain_Length & 2 & FP \& Jap & $\begin{array}{l}15,480,976- \\
16,798,043\end{array}$ & 27 & $\begin{array}{c}2.69 \mathrm{E}- \\
12 \\
\end{array}$ & 197 & 0.01 & $\mathrm{~J} 1, \mathrm{~J} 2, \mathrm{~J} 3, \mathrm{~J} 4$ & $\begin{array}{l}\text { panicle } \\
\text { morphology } \\
\text { [Ta 2018] }\end{array}$ & IPR003480 & Transferase \\
\hline 3_GL_jap & Grain_Length & 2 & Jap & $\begin{array}{l}35,638,527- \\
35,927,940 \\
\end{array}$ & 4 & $\begin{array}{c}3.16 \mathrm{E}- \\
11 \\
\end{array}$ & 58 & 0.12 & 13 & & & \\
\hline 4_GW_jap & Grain_Width & 3 & Jap & $3334516-3,532,506$ & 3 & $\begin{array}{c}5.26 \mathrm{E}- \\
09\end{array}$ & 34 & 0.05 & & $\begin{array}{l}\text { Leaf Length } \\
\text { [Phung } \\
\text { 2016] }\end{array}$ & & \\
\hline 5_GS & Grain_Length & 3 & $\begin{array}{l}\text { FP \& Ind \& } \\
\text { Jap }\end{array}$ & $\begin{array}{l}16,520,656- \\
16,908,475\end{array}$ & 30 & $\begin{array}{c}9.26 \mathrm{E}- \\
17\end{array}$ & 53 & 0.10 & & $\begin{array}{l}\text { grain width } \\
\text { and grain } \\
\text { length } \\
\text { [Mansueto } \\
2017, \mathrm{Li} \\
2018 \text { ] }\end{array}$ & & \\
\hline 6_GS & Grain_Width & 3 & FP \& Jap & $\begin{array}{l}17,686,248- \\
20,833,777\end{array}$ & 355 & $\begin{array}{c}2.02 \mathrm{E}- \\
13\end{array}$ & 471 & 0.18 & $\mathrm{~J} 2$ & $\begin{array}{l}\text { panicle } \\
\text { morphology } \\
{[\text { Ta 2018] }}\end{array}$ & PWY-861 & $\begin{array}{l}\text { dhurrin } \\
\text { biosynthesis }\end{array}$ \\
\hline 7_GL & Grain_Length & 4 & FP & $\begin{array}{l}12,043,539- \\
13,108,767\end{array}$ & 14 & $\begin{array}{c}5.51 \mathrm{E}- \\
11\end{array}$ & 167 & 0.06 & $\mathrm{~J} 2$ & & IPR001283 & $\begin{array}{l}\text { Cysteine- } \\
\text { rich } \\
\text { secretory } \\
\text { protein }\end{array}$ \\
\hline 8_HD & Heading_Date & 4 & FP & $\begin{array}{l}16,165,354- \\
16,384,087\end{array}$ & 4 & $\begin{array}{c}1.72 \mathrm{E}- \\
08\end{array}$ & 37 & 0.10 & 14 & & $\begin{array}{l}\text { PWY-5733, PWY- } \\
6275\end{array}$ & $\begin{array}{l}\text { Terpenoid } \\
\text { Biosynthesis }\end{array}$ \\
\hline 9_PL & Panicle_Length & 5 & FP & $667,557-767,557$ & 2 & $\begin{array}{c}6.17 \mathrm{E}- \\
08\end{array}$ & 20 & 0.38 & 15 & & & \\
\hline 10_GS & Grain_Width & 5 & FP \& Ind & $4,802,345-5,383,914$ & 57 & $\begin{array}{c}2.40 \mathrm{E}- \\
11\end{array}$ & 75 & 0.18 & & $\begin{array}{l}\text { grain width } \\
\text { and grain } \\
\text { length } \\
\text { [Mansueto }\end{array}$ & & \\
\hline
\end{tabular}




\begin{tabular}{|c|c|c|c|c|c|c|c|c|c|c|c|c|}
\hline & & & & & & & & & & $\begin{array}{l}\text { 2017, Li } \\
\text { 2018] }\end{array}$ & & \\
\hline 11_GL & Grain_Length & 6 & FP \& Ind & $1,561,006-1,664,716$ & 16 & $\begin{array}{c}2.68 \mathrm{E}- \\
10\end{array}$ & 17 & 0.17 & & & & \\
\hline 12_GL & Grain_Length & 6 & FP \& Ind & $6,680,831-7,190,137$ & 51 & $\begin{array}{c}1.81 \mathrm{E}- \\
14\end{array}$ & 78 & 0.17 & 14,15 & & GO:0071554 & $\begin{array}{l}\text { cell wall } \\
\text { organization } \\
\text { or } \\
\text { biogenesis }\end{array}$ \\
\hline 13 GL & Grain_Length & 6 & $\mathrm{FP}$ & $7,453,914-7,553,914$ & 2 & $\begin{array}{c}5.90 \mathrm{E}- \\
08\end{array}$ & 13 & 0.11 & 12 & & PWY-4203 & $\begin{array}{l}\text { volatile } \\
\text { benzenoid } \\
\text { biosynthesis } \\
\text { | }\end{array}$ \\
\hline 14_PL & Panicle_Length & 6 & $\mathrm{FP}$ & $\begin{array}{l}20,400,110- \\
20,500,110\end{array}$ & 2 & $\begin{array}{c}2.72 \mathrm{E}- \\
08\end{array}$ & 13 & 0.40 & 15 & & & \\
\hline 15_GL_jap & Grain_Length & 7 & Jap & $\begin{array}{l}11519294- \\
12,296,525\end{array}$ & 3 & $\begin{array}{l}5.76 \mathrm{E}- \\
08\end{array}$ & 99 & 0.04 & $J 4$ & & & \\
\hline 16_FP & Floret_Pubescence & 8 & FP & $\begin{array}{l}18,004,654- \\
18,104,654\end{array}$ & 2 & $\begin{array}{c}1.64 \mathrm{E}- \\
08\end{array}$ & 17 & 0.14 & $\mathrm{~J} 1$ & & & \\
\hline 17_FP & Floret_Pubescence & 8 & FP & $\begin{array}{l}26,175,268- \\
26,275,268\end{array}$ & 2 & $\begin{array}{c}6.06 \mathrm{E}- \\
08\end{array}$ & 15 & 0.05 & & & IPR001607 & $\begin{array}{l}\text { Zinc finger, } \\
\text { UBP-type }\end{array}$ \\
\hline 18_FP & Floret_Pubescence & 9 & FP & $6,656,837-7,940,621$ & 51 & $\begin{array}{c}7.23 \mathrm{E}- \\
12 \\
\end{array}$ & 168 & 0.16 & 14 & & IPR004158 & DUF247 \\
\hline 19_HD & Heading_Date & 9 & FP & $\begin{array}{l}14,067,272- \\
14,807,406\end{array}$ & 7 & $\begin{array}{c}6.86 \mathrm{E}- \\
09\end{array}$ & 115 & 0.10 & 12 & & GO:0002438 & $\begin{array}{l}\text { response to } \\
\text { stimulus }\end{array}$ \\
\hline 20_GW_jap & Grain_Width & 10 & Jap & $1,098,998-1,404,807$ & 6 & $\begin{array}{c}3.61 \mathrm{E}- \\
12\end{array}$ & 52 & 0.21 & & & & \\
\hline 21_LW & Leaf_width & 12 & FP & $\begin{array}{l}17,445,137- \\
17,561,823\end{array}$ & 2 & $\begin{array}{c}2.14 \mathrm{E}- \\
09\end{array}$ & 13 & 0.08 & & & & \\
\hline
\end{tabular}

$1015 *$ for full list of enriched (Max p-value 0.05 with Bonferroni correction) protein domains, Gene Ontology Biological Processes and Meta-Cyc pathways and

1016 underlying genes see Additional file 1: Table S9. ^ $\mathrm{F}_{\mathrm{st}}$ between the 43 accessions in subpopulation I5 and the 190 accessions in subpopulations I2, I3 and I4.

1017 FP: full panel; Ind: Indica subpanel; Jap: Japonica subpanel; Chrom: chromosome; Sig SNPs nb: number of significant SNPs. References: Ta 2018 [10],

1018 Phung 2016 [9], Mansueto 2017 [25], Li 2018 [27]. 
1019 Table 2: 52 regions under selection in the Indica 15 subpopulation. Detailing the overlap of selected regions with published QTLs for Vietnamese rice

1020 populations and the QTLs described in Table 1, selected regions in Indica and Japonica subpopulations, and published selected regions [Lyu 2014, Xie 2015].

\begin{tabular}{|c|c|c|c|c|c|c|c|c|c|c|c|c|c|}
\hline \multirow[b]{2}{*}{ Region } & \multirow[b]{2}{*}{ Chrom } & \multirow[b]{2}{*}{ Segment position (bp) } & \multirow[b]{2}{*}{$\begin{array}{c}\text { ^ FST } \\
15 \text { vs } \\
12,13,14 \\
\text { (a) }\end{array}$} & \multirow[b]{2}{*}{$\begin{array}{l}\text { genes } \\
\text { per } \\
\text { region }\end{array}$} & \multirow[b]{2}{*}{$\begin{array}{l}\text { Overlap } \\
\text { Indica }\end{array}$} & \multirow[b]{2}{*}{$\begin{array}{l}\text { Overlap } \\
\text { japonica }\end{array}$} & \multicolumn{3}{|c|}{ Number of overlapping genes } & \multicolumn{2}{|l|}{$\begin{array}{l}\text { Enrichment } \\
\text { phytozome }\end{array}$} & \multirow[b]{2}{*}{$\begin{array}{l}\text { A FST } \\
! 5 \text { vs } \\
12,13 \\
14 \text { (b) }\end{array}$} & \multirow[b]{2}{*}{$\begin{array}{l}\text { Overlap with QTLs } \\
\text { (c) }\end{array}$} \\
\hline & & & & & & & $\begin{array}{c}\text { ecotype } \\
\text { differentia } \\
\text { ted } \\
\text { genes* }\end{array}$ & $\begin{array}{c}\text { tall } \\
\text { (Ind1)* }\end{array}$ & $\begin{array}{l}\text { semi- } \\
\text { dwarf } \\
\text { (IndlI)* }\end{array}$ & identifier & function & & \\
\hline $15 \_1$ & 1 & $5,563,164-6,569,946$ & 0.28 & 138 & 12,14 & $\mathrm{~J} 1, \mathrm{~J} 3, \mathrm{~J} 4$ & & 39 & & PWY-6303 & $\begin{array}{l}\text { methyl indole-3-acetate } \\
\text { interconversion }\end{array}$ & 0.22 & $\begin{array}{l}\text { Root mass [Phung } \\
\text { 2016], panicle } \\
\text { morphology [Ta } \\
\text { 2018] }\end{array}$ \\
\hline $15 \_2$ & 1 & $12,270,588-12,957,024$ & 0.33 & 94 & & $\mathrm{~J} 3$ & & & & PWY-7445 & $\begin{array}{l}\text { luteolin triglucuronide } \\
\text { degradation }\end{array}$ & 0.27 & \\
\hline $15 \_3$ & 1 & $17,910,736-18,069,653$ & 0.23 & 24 & & & & & & & & & \\
\hline $15 \_4$ & 1 & $21,880,287-22,319,111$ & 0.05 & 59 & 11 & & 1 & & & IPR004883 & $\begin{array}{l}\text { Lateral organ boundaries, } \\
\text { LOB }\end{array}$ & 0.03 & \\
\hline $15 \_5$ & 1 & $37,850,965-38,378,420$ & 0.64 & 84 & 11 & & & & & IPR004183 & $\begin{array}{l}\text { Extradiol ring-cleavage } \\
\text { dioxygenase }\end{array}$ & 0.72 & $\begin{array}{l}\text { Leaf mass [Hoang } \\
\text { 2019] }\end{array}$ \\
\hline $15 \_6$ & 1 & $40,530,842-40,679,473$ & 0.15 & 19 & 12,13 & & & & 19 & PWY-5980 & $\begin{array}{l}\text { xylogalacturonan } \\
\text { biosynthesis }\end{array}$ & 0.18 & $\begin{array}{l}\text { Jasmonate SHL [To } \\
\text { 2019] }\end{array}$ \\
\hline $15 \_7$ & 1 & $41,340,158-41,769,828$ & 0.31 & 65 & & & & & & GO:0005975 & $\begin{array}{l}\text { carbohydrate metabolic } \\
\text { process }\end{array}$ & 0.37 & \\
\hline $15 \_8$ & 2 & $677-354,653$ & 0.39 & 64 & & & & & & & & & \\
\hline $15 \_9$ & 2 & $1,020,920-1,369,616$ & 0.30 & 64 & 11 & & & & & IPR000864 & Proteinase inhibitor I13 & 0.51 & \\
\hline $15 \_10$ & 2 & $2,050,537-2,469,973$ & 0.24 & 60 & 14 & $\mathrm{~J} 2, \mathrm{~J} 3$ & & & & IPR008930 & $\begin{array}{l}\text { Terpenoid cyclases/protein } \\
\text { prenyltransferase alpha- } \\
\text { alpha toroid }\end{array}$ & 0.29 & \\
\hline $15 \_11$ & 2 & $3,101,251-3,324,479$ & 0.25 & 44 & & & & & & IPR001611 & Leucine-rich repeat & 0.18 & \\
\hline $15 \_12$ & 2 & $3,765,987-4,489,973$ & 0.25 & 114 & & & & & & GO:0006952 & defense response & 0.24 & \\
\hline 15_13 & 2 & $7,320,174-7,989,585$ & 0.07 & 81 & 14 & & & & & GO:0006979 & $\begin{array}{l}\text { response to oxidative } \\
\text { stress }\end{array}$ & 0.05 & \\
\hline 15_14 & 2 & $20,981,182-21,185,348$ & 0.44 & 26 & & & & & & & & & \\
\hline $15 \_15$ & 2 & $24,920,001-25,369,666$ & 0.12 & 62 & & & & & 8 & GO:0006559 & $\begin{array}{l}\text { L-phenylalanine catabolic } \\
\text { process }\end{array}$ & 0.17 & \\
\hline 15_16 & 2 & $28,191,142-29,329,745$ & 0.24 & 168 & 13 & & & & & & & & $\begin{array}{l}\text { Jasmonate RTL [To } \\
\text { 2019] }\end{array}$ \\
\hline $15 \_17$ & 3 & $6,691,656-8,177,456$ & 0.39 & 224 & 11 & $J 3, J 4$ & & & & IPR000971 & Globin & 0.63 & \\
\hline $15 \_18$ & 3 & $12,650,311-12,946,658$ & 0.21 & 45 & & & & & & & & & \\
\hline $15 \_19$ & 3 & $15,380,808-15,879,517$ & 0.10 & 71 & 13 & & & & 23 & IPR001563 & $\begin{array}{l}\text { Peptidase } \mathrm{S} 10 \text {, serine } \\
\text { carboxypeptidase }\end{array}$ & 0.06 & \\
\hline
\end{tabular}




\begin{tabular}{|c|c|c|c|c|c|c|c|c|c|c|c|c|c|}
\hline $15 \_20$ & 3 & $20,960,124-21,669,162$ & 0.25 & 114 & & & & & & GO:0006813 & potassium ion transport & 0.18 & \\
\hline $15 \_21$ & 3 & $24,370,632-24,999,498$ & 0.23 & 74 & 11,13 & & & & 13 & & & & \\
\hline $15 \_22$ & 3 & $25,193,549-25,587,517$ & 0.28 & 55 & & & & 7 & 9 & & & & \\
\hline $15 \_23$ & 3 & $27,910,148-29,199,870$ & 0.34 & 188 & $12,13,14$ & & 17 & 6 & 85 & GO:0023014 & protein phosphorylation & 0.49 & \\
\hline $15 \_24$ & 3 & $29,431,523-29,589,724$ & 0.45 & 21 & 14 & & 1 & 2 & & & & & \\
\hline $15 \_25$ & 3 & $33,372,038-33,639,859$ & 0.42 & 45 & 13 & & & & & & & & \\
\hline $15 \_26$ & 4 & $62,390-489,186$ & 0.23 & 62 & & & & & & IPR006115 & $\begin{array}{l}\text { 6-phosphogluconate } \\
\text { dehydrogenase, NADP- } \\
\text { binding }\end{array}$ & 0.21 & \\
\hline $15 \_27$ & 4 & $5,251,107-5,436,839$ & 0.12 & 25 & & & & & & PWY-2981 & $\begin{array}{l}\text { diterpene phytoalexins } \\
\text { precursors biosynthesis }\end{array}$ & 0.10 & \\
\hline $15 \_28$ & 4 & $33,073,892-33,369,648$ & 0.43 & 46 & & & & & & & & & \\
\hline $15 \_29$ & 4 & $34,813,879-35,098,724$ & 0.62 & 44 & 12 & & & 8 & & & & & \\
\hline $15 \_30$ & 5 & $386,347-1,563,159$ & 0.28 & 190 & & & & & & & & & 9_PL \\
\hline 15_31 & 6 & $6,640,258-7,189,250$ & 0.17 & 80 & $11,12,14$ & & & 7 & & & & & 12_GL \\
\hline $15 \_32$ & 6 & $7,860,166-8,418,475$ & 0.38 & 70 & 13,14 & $\mathrm{~J} 3$ & & 3 & & PWY-6917 & vernolate biosynthesis III & 0.37 & $\begin{array}{l}\text { Leaf length [Phung } \\
\text { 2016] }\end{array}$ \\
\hline 15_33 & 6 & $19,470,641-20,499,968$ & 0.58 & 165 & 11 & & & & & IPR001841 & Zinc finger, RING-type & 0.74 & $\begin{array}{l}\text { Panicle length [Ta } \\
\text { 2018], root length } \\
\text { and number } \\
\text { [Phung 2016] }\end{array}$ \\
\hline $15 \_34$ & 7 & $19,443,608-19,825,988$ & 0.19 & 54 & 11 & $\mathrm{J4}$ & & & & IPR021470 & $\begin{array}{l}\text { Protein of unknown } \\
\text { function DUF } 3123\end{array}$ & 0.17 & $\begin{array}{l}\text { Water content } \\
\text { after drought } \\
\text { [Hoang 2019] }\end{array}$ \\
\hline $15 \_35$ & 7 & $29,030,233-29,677,525$ & 0.76 & 97 & 13 & & & & & & & & $\begin{array}{l}\text { Root depth [Phung } \\
\text { 2016] }\end{array}$ \\
\hline $15 \_36$ & 8 & $3,484,045-3,758,632$ & 0.35 & 39 & 13,14 & & & & & & & & $\begin{array}{l}\text { Jasmonate SHL [To } \\
\text { 2019] }\end{array}$ \\
\hline $15 \_37$ & 8 & $5,052,017-5,809,093$ & 0.38 & 127 & 13,14 & & & & & IPR001929 & Germin & 0.55 & $\begin{array}{l}\text { Panicle branches } \\
\text { [Ta 2018] }\end{array}$ \\
\hline $15 \_38$ & 8 & $19,431,460-20,459,346$ & 0.22 & 149 & 11 & & & & & IPR010683 & $\begin{array}{l}\text { Protein of unknown } \\
\text { function DUF1262 }\end{array}$ & 0.23 & \\
\hline $15 \_39$ & 8 & $24,300,313-24,859,863$ & 0.23 & 92 & & & & & & IPR002935 & $\begin{array}{l}\text { O-methyltransferase, } \\
\text { family } 3\end{array}$ & 0.24 & \\
\hline $15 \_40$ & 9 & $14,820,651-15,259,615$ & 0.24 & 61 & & $J 2, J 4$ & 2 & & & IPR002867 & IBR domain & 0.32 & \\
\hline 15_41 & 9 & $16,430,191-18,049,085$ & 0.54 & 252 & 12,13 & & & & & PWY-6303 & $\begin{array}{l}\text { methyl indole-3-acetate } \\
\text { interconversion }\end{array}$ & & \\
\hline $15 \_42$ & 9 & $18,292,494-18,798,654$ & 0.49 & 78 & $12,13,14$ & & & & & IPR029071 & Ubiquitin-related domain & 0.89 & \\
\hline $15 \_43$ & 9 & $19,710,325-20,229,472$ & 0.11 & 83 & & & & & & PWY-5176 & $\begin{array}{l}\text { coumarin biosynthesis (via } \\
\text { 2-coumarate) }\end{array}$ & 0.09 & \\
\hline $15 \_44$ & 10 & $5,381,471-5,869,967$ & 0.27 & 62 & & & & & & PWY-6303 & $\begin{array}{l}\text { methyl indole-3-acetate } \\
\text { interconversion }\end{array}$ & 0.64 & \\
\hline $15 \_45$ & 10 & $10,528,884-11,139,609$ & 0.38 & 118 & & & & & & IPR027923 & Hydrophobic seed protein & 0.76 & \\
\hline $15 \_46$ & 10 & $11,991,467-12,409,929$ & 0.26 & 69 & & & & & & & & & \\
\hline
\end{tabular}




\begin{tabular}{|c|c|c|c|c|c|c|c|c|c|c|c|c|}
\hline $15 \_47$ & 10 & $18,732,199-19,209,687$ & 0.51 & 80 & 14 & & & 64 & IPR002885 & Pentatricopeptide repeat & 0.48 & \\
\hline $15 \_48$ & 11 & $2,510,079-3,239,747$ & 0.38 & 109 & 11,14 & & 56 & & GO:0050794 & $\begin{array}{l}\text { regulation of cellular } \\
\text { process }\end{array}$ & 0.45 & $\begin{array}{l}\text { Water content } \\
\text { after drought } \\
\text { [Hoang 2019] }\end{array}$ \\
\hline $15 \_49$ & 11 & $4,590,276-5,937,318$ & 0.35 & 200 & & J1 & 3 & 14 & IPR001810 & F-box domain & 0.38 & $\begin{array}{l}\text { Root number } \\
\text { [Phung 2016] }\end{array}$ \\
\hline $15 \_50$ & 11 & $6,060,058-6,179,872$ & 0.23 & 20 & & & & & & & & \\
\hline $15 \_51$ & 12 & $50,720-659,181$ & 0.30 & 108 & & & & & & & & \\
\hline $15 \_52$ & 12 & $25,861,119-26,518,838$ & 0.11 & 93 & 12,13 & & & & & & & \\
\hline
\end{tabular}

$1022 *$ for full list of enriched (Max p-value 0.05 with Bonferroni correction) protein domains, Gene Ontology Biological Processes and Meta-Cyc pathways and

1023 underlying genes see Additional file 1: Table S13. ^ $\mathrm{F}_{\mathrm{ST}}$ between the 43 samples in subpopulation I5 and the 190 samples in subpopulations I2, I3 and I4 (a)

1024 mean $\mathrm{F}_{\mathrm{ST}}$ for all the genes in the selected region. (b) mean $\mathrm{F}_{\mathrm{ST}}$ for the genes showing functional enrichment. (c) details in Additional file 1: Table S14 and

1025 S15. References Phung 2016 [9], Ta 2018 [10], Hoang 2019_1 [12] , To 2019 [13], Hoang 2019_2 [11]. \& Overlap withregions selected in other Indica

1026 subpopulations. \&\& Overlap with regions selected in other Japonica subpopulations. 
1028 Table 3: Candidate genes under selection in the Indica 15 subpopulation. Functional annotation of the 56 candidate genes and overlap with genes selected

1029 in previous studies [17, 18].

\begin{tabular}{|c|c|c|c|c|c|c|c|c|c|c|}
\hline Region & $\begin{array}{l}\text { ^ FST !5 vs } \\
12,13,14 \text { (a) }\end{array}$ & Gene (MSU) & Gene (RAP) & $\begin{array}{l}\text { ^ FST I5 vs } \\
12,13,14 \text { (b) }\end{array}$ & Gene function & Symbol & $\begin{array}{c}* \\
\text { Selec } \\
\text { ted } \\
\text { in } \\
\end{array}$ & impact & Ref & $\begin{array}{l}\text { Gene Ontology } \\
\text { annotation }\end{array}$ \\
\hline $15 \_5$ & 0.644 & $\begin{array}{l}\text { LOC_Os01g65 } \\
670\end{array}$ & $\begin{array}{l}\text { Os01g087870 } \\
0\end{array}$ & 0.909 & $\begin{array}{l}\text { amino acid transporter, putative, } \\
\text { expressed }\end{array}$ & $\begin{array}{l}\text { OsAAP6 } \mid \mathrm{qPC} \\
1\end{array}$ & & NA & $\begin{array}{l}\text { Peng 2014, } \\
\text { Abbai } 2019\end{array}$ & $\begin{array}{l}\text { amino acid } \\
\text { transmembrane } \\
\text { transport }\end{array}$ \\
\hline $15 \_5$ & & $\begin{array}{l}\text { LOC_Os01g65 } \\
770\end{array}$ & $\begin{array}{l}\text { Os01g088010 } \\
0\end{array}$ & 0.936 & expressed protein - rice specfic & NA & & start_lost & & \\
\hline $15 \_5$ & & $\begin{array}{l}\text { LOC_Os01g65 } \\
904\end{array}$ & $\begin{array}{l}\text { Os01g088180 } \\
0\end{array}$ & 0.788 & expressed protein - rice specfic & NA & & stop_gained & & \\
\hline $15 \_5$ & & $\begin{array}{l}\text { LOC_Os01g66 } \\
030\end{array}$ & $\begin{array}{l}\text { Os01g088310 } \\
0\end{array}$ & 0.651 & $\begin{array}{l}\text { OsMADS2 - MADS-box family gene } \\
\text { with MIKCc type-box, expressed }\end{array}$ & OsMADS2 & & NA & $\begin{array}{l}\text { Lombardo } \\
2017\end{array}$ & $\begin{array}{l}\text { specification of stamen } \\
\text { identity }\end{array}$ \\
\hline $15 \_16$ & 0.243 & $\begin{array}{l}\text { LOC_Os02g47 } \\
310\end{array}$ & $\begin{array}{l}\text { Os02g070160 } \\
0\end{array}$ & 0.564 & $\begin{array}{l}\text { Cyclopropane-fatty-acyl- } \\
\text { phospholipid synthase, putative, } \\
\text { expressed }\end{array}$ & VTE4 & & NA & To 2019 & $\begin{array}{l}\text { vitamin } \mathrm{E} \text { biosynthetic } \\
\text { process }\end{array}$ \\
\hline $15 \_16$ & & $\begin{array}{l}\text { LOC_Os02g47 } \\
350\end{array}$ & $\begin{array}{l}\text { Os02g070190 } \\
0\end{array}$ & 0.666 & $\begin{array}{l}\text { oxidoreductase, short chain } \\
\text { dehydrogenase/reductase family, } \\
\text { putative, expressed }\end{array}$ & NA & & NA & To 2019 & $\begin{array}{l}\text { oxidation-reduction } \\
\text { process }\end{array}$ \\
\hline $15 \_16$ & & $\begin{array}{l}\text { LOC_Os02g47 } \\
400\end{array}$ & $\begin{array}{l}\text { Os02g070240 } \\
0\end{array}$ & 0.501 & $\begin{array}{l}\text { pectinacetylesterase domain } \\
\text { containing protein, expressed }\end{array}$ & NA & & NA & To 2019 & cell wall organization \\
\hline 15_16 & & $\begin{array}{l}\text { LOC_Os02g47 } \\
410\end{array}$ & $\begin{array}{l}\text { Os02g070250 } \\
0\end{array}$ & 0.522 & protein kinase, putative, expressed & NA & & NA & To 2019 & $\begin{array}{l}\text { protein } \\
\text { phosphorylation }\end{array}$ \\
\hline $15 \_16$ & & $\begin{array}{l}\text { LOC_Os02g47 } \\
420\end{array}$ & $\begin{array}{l}\text { Os02g070260 } \\
0\end{array}$ & 0.572 & $\begin{array}{l}\text { ATROPGEF7/ROPGEF7, putative, } \\
\text { expressed }\end{array}$ & OSROPGEF & & NA & To 2019 & $\begin{array}{l}\text { guanyl-nucleotide } \\
\text { exchange factor activity }\end{array}$ \\
\hline $15 \_16$ & & $\begin{array}{l}\text { LOC_Os02g47 } \\
440\end{array}$ & $\begin{array}{l}\text { Os02g070280 } \\
0\end{array}$ & 0.536 & syntaxin, putative, expressed & NA & & NA & To 2019 & $\begin{array}{l}\text { intracellular protein } \\
\text { transport }\end{array}$ \\
\hline 15_16 & & $\begin{array}{l}\text { LOC_Os02g47 } \\
590\end{array}$ & $\begin{array}{l}\text { Os02g070480 } \\
0\end{array}$ & 0.637 & $\begin{array}{l}\text { ornithine carbamoyltransferase, } \\
\text { putative, expressed }\end{array}$ & NA & & NA & To 2019 & $\begin{array}{l}\text { cellular amino acid } \\
\text { metabolic process }\end{array}$ \\
\hline $15 \_17$ & 0.390 & $\begin{array}{l}\text { LOC_Os03g12 } \\
840\end{array}$ & $\begin{array}{l}\text { Os03g023050 } \\
0\end{array}$ & 0.477 & $\begin{array}{l}\text { Inositol 1,3, 4-trisphosphate 5/6- } \\
\text { kinase, putative, expressed }\end{array}$ & $\begin{array}{l}\text { DSM3|Os|TPK } \\
2\end{array}$ & & stop gained & Du 2011 & \\
\hline 15_17 & & $\begin{array}{l}\text { LOC_Os03g13 } \\
010\end{array}$ & $\begin{array}{l}\text { Os03g023260 } \\
0\end{array}$ & 0.837 & $\begin{array}{l}\text { U-box domain containing protein, } \\
\text { expressed }\end{array}$ & $\begin{array}{l}\text { TUD1|DSG1| } \\
\text { ELF1 }\end{array}$ & & NA & $\begin{array}{l}\text { Sakamoto } \\
2017\end{array}$ & $\begin{array}{l}\text { regulation of } \\
\text { brassinosteroid } \\
\text { mediated signaling } \\
\text { pathway }\end{array}$ \\
\hline $15 \_17$ & & $\begin{array}{l}\text { LOC_Os03g13 } \\
140\end{array}$ & $\begin{array}{l}\text { Os03g023390 } \\
0\end{array}$ & 0.879 & $\begin{array}{l}\text { non-symbiotic hemoglobin 2, } \\
\text { putative, expressed }\end{array}$ & $\mathrm{Hb} 1$ & & NA & $\begin{array}{l}\text { Lira-Ruan } \\
2011\end{array}$ & oxygen transport \\
\hline $15 \_17$ & & $\begin{array}{l}\text { LOC_Os03g14 } \\
669\end{array}$ & $\begin{array}{l}\text { Os03g025135 } \\
0\end{array}$ & 0.918 & $\begin{array}{l}\text { core histone } \mathrm{H} 2 \mathrm{~A} / \mathrm{H} 2 \mathrm{~B} / \mathrm{H} 3 / \mathrm{H} 4 \text {, } \\
\text { putative, expressed }\end{array}$ & OsHAP5C & & NA & Kim 2016 & $\begin{array}{l}\text { negative regulation of } \\
\text { long-day } \\
\text { photoperiodism, }\end{array}$ \\
\hline
\end{tabular}




\begin{tabular}{|c|c|c|c|c|c|c|c|c|c|c|}
\hline & & & & & & & & & & flowering \\
\hline $15 \_23$ & 0.338 & $\begin{array}{l}\text { LOC_Os03g49 } \\
500\end{array}$ & $\begin{array}{l}\text { Os03g070170 } \\
0\end{array}$ & 0.719 & $\begin{array}{l}\text { ethylene receptor, putative, } \\
\text { expressed }\end{array}$ & Os-ERS1 & & NA & Yu 2017 & $\begin{array}{l}\text { ethylene-activated } \\
\text { signaling pathway }\end{array}$ \\
\hline $15 \_23$ & & $\begin{array}{l}\text { LOC_Os03g51 } \\
050\end{array}$ & $\begin{array}{l}\text { Os03g071990 } \\
0\end{array}$ & 0.660 & $\begin{array}{l}\text { peptide transporter PTR2, putative, } \\
\text { expressed }\end{array}$ & PTR8 & 1,3 & NA & $\begin{array}{l}\text { LYU } \\
\text { 2012, OUYA } \\
\text { NG 2010 }\end{array}$ & $\begin{array}{l}\text { oligopeptide } \\
\text { transmembrane } \\
\text { transport }\end{array}$ \\
\hline $15 \_25$ & 0.423 & $\begin{array}{l}\text { LOC_Os03g58 } \\
600\end{array}$ & $\begin{array}{l}\text { Os03g080020 } \\
0\end{array}$ & 0.844 & $\begin{array}{l}\text { PAZ domain containing protein, } \\
\text { putative, expressed }\end{array}$ & MEL1 & & NA & Yi 2012 & \\
\hline $15 \_25$ & & $\begin{array}{l}\text { LOC_Os03g58 } \\
630\end{array}$ & $\begin{array}{l}\text { Os03g080070 } \\
0\end{array}$ & 0.886 & thioredoxin, putative, expressed & OsTrxh4 & & NA & Ying 2017 & $\begin{array}{l}\text { oxidation-reduction } \\
\text { process }\end{array}$ \\
\hline 15_29 & 0.618 & $\begin{array}{l}\text { LOC_Os04g58 } \\
740\end{array}$ & None & 0.818 & expressed protein - rice specfic & NA & 2 & start_lost & & \\
\hline 15_29 & & $\begin{array}{l}\text { LOC_Os04g58 } \\
750\end{array}$ & $\begin{array}{l}\text { Os04g068420 } \\
0\end{array}$ & 0.815 & $\begin{array}{l}\text { protein kinase family protein, } \\
\text { putative, expressed }\end{array}$ & OsBSK3 & 2 & NA & Zhang 2016 & $\begin{array}{l}\text { protein modification } \\
\text { process }\end{array}$ \\
\hline $15 \_29$ & & $\begin{array}{l}\text { LOC_Os04g58 } \\
780\end{array}$ & $\begin{array}{l}\text { Os04g068450 } \\
0\end{array}$ & 0.806 & $\begin{array}{l}\text { pentatricopeptide repeat protein, } \\
\text { putative, expressed }\end{array}$ & $\begin{array}{l}\text { WSL5|OsPPR } \\
4\end{array}$ & 2 & NA & Liu 2018 & leaf development \\
\hline 15_29 & & $\begin{array}{l}\text { LOC_Os04g58 } \\
870\end{array}$ & $\begin{array}{l}\text { Os04g068550 } \\
0\end{array}$ & 0.813 & $\begin{array}{l}\text { exo } 70 \text { exocyst complex subunit, } \\
\text { putative, expressed }\end{array}$ & NA & & $\begin{array}{l}\text { splice_accept } \\
\text { or_variant \& } \\
\text { intron_variant }\end{array}$ & Tu 2015 & exocytosis \\
\hline $15 \_29$ & & $\begin{array}{l}\text { LOC_Os04g58 } \\
880\end{array}$ & $\begin{array}{l}\text { Os04g068560 } \\
0\end{array}$ & 0.826 & $\begin{array}{l}\text { exo70 exocyst complex subunit, } \\
\text { putative, expressed }\end{array}$ & $\begin{array}{l}\text { RLS2|OsEXO7 } \\
\text { OA1 }\end{array}$ & & NA & Tu 2015 & exocytosis \\
\hline $15 \_30$ & 0.281 & $\begin{array}{l}\text { LOC_Os05g02 } \\
260\end{array}$ & $\begin{array}{l}\text { Os05g011350 } \\
0\end{array}$ & 0.617 & interacts with OsMPK1 & bip 130 & & stop_gained & Zhou 2019 & \\
\hline 15_33 & 0.584 & $\begin{array}{l}\text { LOC_Os06g34 } \\
360\end{array}$ & $\begin{array}{l}\text { Os06g053450 } \\
0\end{array}$ & 0.959 & $\begin{array}{l}\text { zinc finger, C3HC4 type domain } \\
\text { containing protein, expressed }\end{array}$ & NA & & NA & Zang 2016 & \\
\hline 15_33 & & $\begin{array}{l}\text { LOC_Os06g34 } \\
650\end{array}$ & $\begin{array}{l}\text { Os06g053760 } \\
0\end{array}$ & 0.948 & $\begin{array}{l}\text { zinc finger, C3HC4 type domain } \\
\text { containing protein, expressed }\end{array}$ & NA & & NA & Zang 2016 & \\
\hline 15_33 & & $\begin{array}{l}\text { LOC_Os06g33 } \\
520\end{array}$ & $\begin{array}{l}\text { Os06g052660 } \\
0\end{array}$ & 0.509 & $\begin{array}{l}\text { DEAD/DEAH box helicase, putative, } \\
\text { expressed }\end{array}$ & OsABP & & & $\begin{array}{l}\text { Macovei } \\
2012\end{array}$ & \\
\hline 15_35 & 0.756 & $\begin{array}{l}\text { LOC_Os07g48 } \\
560\end{array}$ & $\begin{array}{l}\text { Os07g068490 } \\
0\end{array}$ & 0.927 & $\begin{array}{l}\text { homeobox domain containing } \\
\text { protein, expressed }\end{array}$ & wox11 & & NA & Zhang 2018 & lateral root formation \\
\hline 15_35 & & $\begin{array}{l}\text { LOC_Os07g48 } \\
640\end{array}$ & $\begin{array}{l}\text { Os07g068580 } \\
0\end{array}$ & 0.953 & $\begin{array}{l}\text { short-chain } \\
\text { dehydrogenase/reductase, putative, } \\
\text { expressed }\end{array}$ & OsSDR & & NA & Kim 2009 & $\begin{array}{l}\text { oxidation-reduction } \\
\text { process }\end{array}$ \\
\hline 15_35 & & $\begin{array}{l}\text { LOC_Os07g48 } \\
680\end{array}$ & $\begin{array}{l}\text { Os07g068630 } \\
0\end{array}$ & 0.955 & $\begin{array}{l}\text { zinc finger, C3HC4 type domain } \\
\text { containing protein, expressed }\end{array}$ & NA & & NA & Zang 2016 & \\
\hline 15_35 & & $\begin{array}{l}\text { LOC_Os07g48 } \\
750\end{array}$ & $\begin{array}{l}\text { Os07g068690 } \\
0\end{array}$ & 0.920 & $\begin{array}{l}\text { alpha-N-arabinofuranosidase, } \\
\text { putative, expressed }\end{array}$ & OsARAF1 & & NA & $\begin{array}{l}\text { Sumiyoshi } \\
2013\end{array}$ & $\begin{array}{l}\text { alpha- } \mathrm{L}- \\
\text { arabinofuranosidase } \\
\text { activity }\end{array}$ \\
\hline 15_35 & & $\begin{array}{l}\text { LOC_Os07g48 } \\
780\end{array}$ & $\begin{array}{l}\text { Os07g068720 } \\
0\end{array}$ & 0.907 & OsCam 1-2 - Calmodulin, expressed & $\begin{array}{l}\text { OsCam1- } \\
\text { 2|OsCam1 }\end{array}$ & & NA & $\begin{array}{l}\text { Saeng- } \\
\text { ngam } \\
2012, \\
\text { Yuenyong } \\
2018\end{array}$ & $\begin{array}{l}\text { calcium-mediated } \\
\text { signaling }\end{array}$ \\
\hline $15 \_35$ & & LOC_Os07g48 & Os07g068770 & 0.901 & transcription factor, putative, & rTGA2.1|Osb & & NA & Delteil & defense response \\
\hline
\end{tabular}




\begin{tabular}{|c|c|c|c|c|c|c|c|c|c|c|}
\hline & & 820 & 0 & & expressed & ZIP63|OsNIF1 & & & $\begin{array}{l}2012, \text { Vem } \\
\text { anna } 2019 \\
\end{array}$ & \\
\hline $15 \_35$ & & $\begin{array}{l}\text { LOC_Os07g48 } \\
830\end{array}$ & $\begin{array}{l}\text { Os07g068790 } \\
0\end{array}$ & 0.931 & $\begin{array}{l}\text { glycosyl transferase } 8 \text { domain } \\
\text { containing protein, putative, } \\
\text { expressed }\end{array}$ & $\begin{array}{l}\text { OsGolS2 |wsi7 } \\
6\end{array}$ & & NA & $\begin{array}{l}\text { Mukherjee } \\
2019\end{array}$ & $\begin{array}{l}\text { galactose metabolic } \\
\text { process }\end{array}$ \\
\hline $15 \_35$ & & $\begin{array}{l}\text { LOC_Os07g48 } \\
920\end{array}$ & $\begin{array}{l}\text { Os07g068880 } \\
0\end{array}$ & 0.916 & $\begin{array}{l}\text { aldehyde dehydrogenase, putative, } \\
\text { expressed }\end{array}$ & OsALDH22 & & NA & Yang 2012 & $\begin{array}{l}\text { oxidation-reduction } \\
\text { process }\end{array}$ \\
\hline 15_37 & 0.380 & $\begin{array}{l}\text { LOC_Os08g09 } \\
110\end{array}$ & $\begin{array}{l}\text { Os08g019030 } \\
0\end{array}$ & 0.904 & $\begin{array}{l}\text { NB-ARC domain containing protein, } \\
\text { expressed }\end{array}$ & NA & & stop_gained & & ADP binding \\
\hline 15_41 & 0.539 & $\begin{array}{l}\text { LOC_Os09g28 } \\
280\end{array}$ & $\begin{array}{l}\text { Os09g045590 } \\
0\end{array}$ & 0.654 & $\begin{array}{l}\text { gibberellin receptor GID1L2, } \\
\text { putative, expressed }\end{array}$ & NA & & NA & & \\
\hline 15_41 & & $\begin{array}{l}\text { LOC_Os09g28 } \\
840\end{array}$ & $\begin{array}{l}\text { Os09g046310 } \\
0\end{array}$ & 0.654 & $\begin{array}{l}\text { OsSCP43 - Putative Serine } \\
\text { Carboxypeptidase homologue, } \\
\text { expressed }\end{array}$ & NA & & NA & & \\
\hline 15_42 & 0.485 & $\begin{array}{l}\text { LOC_Os09g30 } \\
340\end{array}$ & $\begin{array}{l}\text { Os09g048120 } \\
0\end{array}$ & 0.971 & $\begin{array}{l}\text { photosystem I reaction center } \\
\text { subunit, chloroplast precursor, } \\
\text { putative, expressed }\end{array}$ & PSAG & & NA & Park 2012 & photosynthesis \\
\hline $15 \_42$ & & $\begin{array}{l}\text { LOC_Os09g30 } \\
360\end{array}$ & $\begin{array}{l}\text { Os09g048140 } \\
0\end{array}$ & 0.973 & $\begin{array}{l}\text { caffeoyl-CoA O-methyltransferase, } \\
\text { putative, expressed }\end{array}$ & NA & & NA & & $\begin{array}{l}\text { secondary metabolic } \\
\text { process }\end{array}$ \\
\hline $15 \_42$ & & $\begin{array}{l}\text { LOC_Os09g30 } \\
380\end{array}$ & $\begin{array}{l}\text { Os09g048160 } \\
0\end{array}$ & 0.966 & $\begin{array}{l}\text { AP005392-AK108636 - NBS/LRR } \\
\text { genes that are S-rich, divergent TIR, } \\
\text { divergent NBS, expressed }\end{array}$ & NA & & NA & & recombinational repair \\
\hline $15 \_42$ & & $\begin{array}{l}\text { LOC_Os09g30 } \\
400\end{array}$ & $\begin{array}{l}\text { Os09g048170 } \\
0\end{array}$ & 0.954 & WRKY90, expressed & OsWRKY80 & & NA & Peng 2016 & $\begin{array}{l}\text { regulation of } \\
\text { transcription, DNA- } \\
\text { templated }\end{array}$ \\
\hline $15 \_42$ & & $\begin{array}{l}\text { LOC_Os09g30 } \\
410\end{array}$ & $\begin{array}{l}\text { Os09g048180 } \\
0\end{array}$ & 0.961 & expressed protein & NA & & NA & & $\begin{array}{l}\text { iron-sulfur cluster } \\
\text { assembly }\end{array}$ \\
\hline $15 \_42$ & & $\begin{array}{l}\text { LOC_Os09g31 } \\
019\end{array}$ & $\begin{array}{l}\text { Os09g048320 } \\
0\end{array}$ & 0.942 & $\begin{array}{l}\text { ubiquitin fusion protein, putative, } \\
\text { expressed }\end{array}$ & NA & & NA & Chen 2017 & \\
\hline $15 \_47$ & 0.508 & $\begin{array}{l}\text { LOC_Os10g35 } \\
260\end{array}$ & $\begin{array}{l}\text { Os10g049540 } \\
0\end{array}$ & 0.703 & $\begin{array}{l}\text { Rf1, mitochondrial precursor, } \\
\text { putative, expressed }\end{array}$ & NA & 3 & NA & & \\
\hline $15 \_47$ & & $\begin{array}{l}\text { LOC_Os10g35 } \\
540\end{array}$ & $\begin{array}{l}\text { Os10g049850 } \\
0\end{array}$ & 0.783 & $\begin{array}{l}\text { hydrolase, alpha/beta fold family } \\
\text { domain containing protein, } \\
\text { expressed }\end{array}$ & NA & 3 & NA & & catalytic activity \\
\hline $15 \_47$ & & $\begin{array}{l}\text { LOC_Os10g35 } \\
560\end{array}$ & $\begin{array}{l}\text { Os10g049870 } \\
0\end{array}$ & 0.692 & expressed protein & OsSFR6 & 3 & NA & $\begin{array}{l}\text { de Freitas } \\
2019\end{array}$ & $\begin{array}{l}\text { response to osmotic } \\
\text { stress }\end{array}$ \\
\hline $15 \_47$ & & $\begin{array}{l}\text { LOC_Os10g35 } \\
604\end{array}$ & $\begin{array}{l}\text { Os10g049920 } \\
0\end{array}$ & 0.661 & expressed protein & NA & 3 & stop_gained & & \\
\hline $15 \_47$ & & $\begin{array}{l}\text { LOC_Os10g35 } \\
640\end{array}$ & $\begin{array}{l}\text { Os10g049950 } \\
0\end{array}$ & 0.700 & $\begin{array}{l}\text { Rf1, mitochondrial precursor, } \\
\text { putative, expressed }\end{array}$ & $\mathrm{Rf} 1 \mathrm{~b}$ & 3 & NA & & protein binding \\
\hline $15 \_48$ & 0.378 & $\begin{array}{l}\text { LOC_Os11g06 } \\
390\end{array}$ & $\begin{array}{l}\text { Os11g016310 } \\
0\end{array}$ & 0.746 & actin, putative, expressed & OsACTIN2 & 2 & NA & & $\begin{array}{l}\text { ATP binding,auxin } \\
\text { signalling }\end{array}$ \\
\hline $15 \_48$ & & $\begin{array}{l}\text { LOC_Os11g06 } \\
410\end{array}$ & $\begin{array}{l}\text { Os11g016350 } \\
0\end{array}$ & 0.841 & homeodomain, putative, expressed & SAB18 & 2 & NA & & stress response \\
\hline $15 \_48$ & & LOC_Os11g06 & None & 0.715 & ribosome inactivating protein, & NA & & NA & & \\
\hline
\end{tabular}




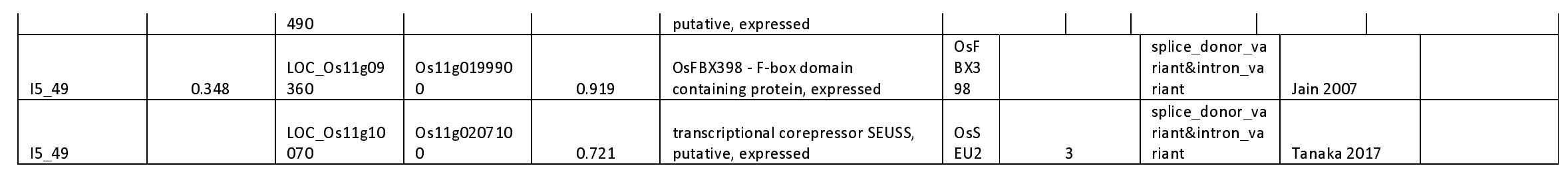

1030

${ }^{\wedge} \mathrm{F}_{\mathrm{ST}}$ between the 43 samples in subpopulation I5 and the 190 samples in subpopulations I2, I3 and I4 (a) mean $\mathrm{F}_{\mathrm{ST}}$ for all the genes in the selected region (b)

1031

A

1032 mean $\mathrm{F}_{\text {ST }}$ per gene. Allele plots for the "High impact" within genes are shown in Additional file 6: Figure S21. References: Ta 2018 [10], Peng 2014 [62],

1033 Abbai 2019 [63], Lombardo 2017 [64], To 2019 [13], Du 2011 [65], Sakamoto 2017 [66], Lira-Ruan 2011 [67], Kim 2016 [68], Yu 2017 [69], Lyu 2014

1034 [18], Ouyang 2010 [35], Yi 2012 [70], Ying 2017 [71], Zhang 2016 [38], Liu 2018 [39], Tu 2015 [72], Zhou 2019 [28], Zang 2016 [73], Macovei 2012 [40],

1035 Zhang 2018 [36], Kim 2009 [37], Zang 2016 [73], Sumiyoshi 2013 [74], Saeng-ngam 2012 [75], Yuenyong 2018 [76], Delteil 2012 [77], Vemanna 2019

1036 [43], Mukherjee 2019 [78], Yang 2012 [79], Park 2012 [80], Peng 2016 [62], Chen 2017 [81], de Freitas 2019 [41], Jain 2007 [42], Tanaka 2017 [82]. *1.

1037 ecotype differentiated genes (Lyu et al. [18]). *2. tall (Ind1) (Xie et al. [17]). *3. semi-dwarf (IndII) (Xie et al. [17]). 
1038 Figure 1: Population structure and location of the Indica and Japonica subpopulations within

1039 Vietnam.

1040 a STRUCTURE results (mean of 10 replicates) at K=5 for 426 Indica subtypes. Each colour

1041 represents one subpopulation. Each accession is represented by a vertical bar and the length of each

1042 coloured segment in each bar represents the proportion contributed by each subpopulation. The cut off

1043 for inclusion in each subpopulation is 0.6. The number of samples in each subpopulation is shown

1044 above, a further 48 samples were classified as admixed. b STRUCTURE results (mean of 10

1045 replicates) at $\mathrm{K}=4$ for 211 Japonica subtypes. The cut off for inclusion in each subpopulation is 0.6.

1046 The number of samples in each subpopulation is shown above, a further 8 samples were classified as

1047 admixed. c STRUCTURE results for the I5 subpopulation expanded to show individual samples. d

1048 The proportion of each population originating from each of the 8 regions in Vietnam (based on a

1049 subset of 377 samples, 54\% of Indica samples and 85\% of Japonica samples).

1050

1051 Figure 2: PCA analysis of Indica and Japonica Vietnamese subpopulations.

1052 a PCA analysis of 426 accessions from Vietnam using the top two components to separate the five

1053 Indica subpopulations. The ellipses show the 95\% confidence interval. b PCA analysis of 211

1054 accessions from Vietnam using the top two components to separate the four Japonica subpopulations.

1055 The ellipses show the $95 \%$ confidence interval.

1056

1057 Figure 3: PCO analysis of Indica and Japonica Vietnamese subpopulations.

1058 a PCO analysis of 1605 Indica samples (omitting the samples classified as XI-adm and Ind-adm

1059 outside Vietnam for clarity). The ellipses show the 95\% confidence interval for the K15_new

1060 subpopulations (the K15_3KRGP and five Vietnamese Indica subpopulations are shown in Figure

1061 S5). $\mathrm{X}=\mathrm{PC} 1, \mathrm{Y}=\mathrm{PC} 4, \mathrm{Z}=\mathrm{PC} 5 . \mathbf{b}$ PCO analysis of 982 Japonica samples (omitting the samples

1062 classified as GJ-adm and Jap-adm outside Vietnam for clarity) showing the K15_new subpopulations

1063 (the K15_3KRGP and four Vietnamese Japonica subpopulations are shown in Figure S6) X= PC3,

$1064 \mathrm{Y}=\mathrm{PC} 4, \mathrm{Z}=\mathrm{PC} 5$.

1065 


\section{Figure 4: Histograms comparing the Indica and Japonica subtypes and the I1 and I5}

\section{7 subpopulations.}

1068 Histogram are shown for 8 of the 13 traits used in the GWAS analysis. The Japonica and Indica

1069 subtypes are shown in green and purple respectively and underneath a histogram is shown for a subset

1070 of the Indica values comparing subpopulations I1 and I5. The mean value is shown by a dotted line

1071 and the $\mathrm{p}$ value (T-test) is shown at the top of each plot. A ggpairs histogram and correlation plot is

1072 available for all 13 traits in Additional file 2: Figure S7, Figure S8.

1074 Figure 5: The distribution of 21 QTL.

107521 significant associations for 8 of the 13 traits $\left(-\log _{10}\right.$ ( $\mathrm{p}$ value) $\geq 8.0$ ). The 33 individual associations for the full panel and the Japonica and Indica subpanels were merged to form the 21 final QTLs. The QTLs for grain length, grain width and grain length/width ratio were merged into QTLs for grain size, these are labelled in brown. The remaining QTLs are labelled in black; Leaf width (LW), Panicle

1079 Length (PL), Heading Date (HD), Floret Pubescence (FP), Diameter Internode (DI). Regions smaller 1080 than $100 \mathrm{~kb}$ are extended to 50kb either side of SNP with maximum $\mathrm{p}$ value. Centromeric regions are shown as $100 \mathrm{~kb}$ regions in dark grey.

\section{Figure 6: XP-CLR scores and regions of selection.}

1084 a Selected regions for the five Indica subpopulations covering 5.4\%, 6.1\%, 5.3\%, 6.3\% and 8.1\% of

1085 the genome for I1, I2, I3, I4 and I5 respectively. Centromeric regions are shown as $100 \mathrm{~kb}$ regions in

1086 dark grey. b Selected region for the four Japonica subpopulations covering 4.3\%, 4.5\%, 3.7\% and

$10874.9 \%$ of the genome for J1, J2, J3 and J4 respectively. $\mathbf{c}$ and $\mathbf{d}$ Mean XP-CLR score across the whole

1088 genome for each comparison between all Indica (c) and Japonica (d) subpopulations. Darker colours

1089 indicate higher selection scores.

1090

1091 Figure 7: Vietnamese QTLs and their overlap with selected regions in the I5 subpopulation.

1092 QTLs from 5 published studies [9-13] and from this study are plotted along each chromosome. The

1093 QTLs which overlap with 14 of the regions selected in the I5 subpopulation are highlighted. The 
bioRxiv preprint doi: https://doi.org/10.1101/2020.07.07.191981; this version posted July 8, 2020. The copyright holder for this preprint (which was not certified by peer review) is the author/funder, who has granted bioRxiv a license to display the preprint in perpetuity. It is made available under aCC-BY-ND 4.0 International license.

1094 mean $\mathrm{F}_{\text {ST }}$ per region between the 43 samples in the $\mathrm{I} 5$ subpopulation and the 190 samples in the I2, I3

1095 and I4 subpopulation is shown for these 14 regions.

1096 
1098

1099 Table S1. Name and details of $\mathbf{6 7 2}$ rice varieties. Detailing read number, mapping statistics,

1100 Vietnamese National Genebank number, local name, location, characteristic, subtype and

1101 subpopulation.

1102

1103 Table S2. Name and details of 3,635 rice varieties. Detailing the new subpopulation and PCO 1104 analysis.

1105

1106 Table S3. Phenotypic measurements for 20 traits for 672 samples. Detailing individual

1107 measurements for each sample, description of phenotypes, statistics for all samples and individually

1108 for the Indica and Japonica subtypes. Phenotypes are available for around $75 \%$ of the samples.

1109

1110 Table S4. Phenotype abbreviations and details.

1111

1112 Table S5. Phenotype statistics (mean and coefficient of variation) and population comparisons.

1113

1114 Table S6. Diversity $(\pi)$ of each subpopulation.

1115

1116 Table S7. GWAS results. List of the 21 QTL and the positions of the individual QTLs for each

1117 panel.

1118

1119 Table S8. Gene lists for the 21 QTL.

1120

1121 Table S9. Annotation of QTL using PhytoMine. Enrichment analysis for protein domain, Meta-Cyc

1122 pathway and Geno Ontology using PhytoMine.

1123 
1124 Table S10. Summary of XP-CLR comparisons for the Indica and Japonica subpopulations.

1125 Detailing the XP-CLR mean, cut off and number of regions for each comparison.

1127 Table S11. List of genes selected in each subpopulation.

1129 Table S12. List of genes selected in each region for Indica I5 subpopulation.

1131 Table S13. Annotation of $\mathbf{I 5}$ selected regions using PhytoMine. List of all genes within each of the

113252 selected regions and the results of PhytoMine Enrichment analysis for protein domain, Meta-Cyc

1133 pathway and Geno Ontology using PhytoMine.

1135 Table S14. Overlap of the selected regions in Indica subpopulations with QTL found in

1136 Vietnamese rice datasets.

1138 Table S15. Overlap of the selected regions in Japonica subpopulations with QTL found in

1139 Vietnamese rice datasets.

Table S16. List of genes selected in I5 subpopulation. Detailing MSU and RAP gene ID, annotation 1142 and enrichment in Phytomine, high impact SNPs and mean $\mathrm{F}^{\mathrm{st}}$

1144 Table S17. List of 21 genes related to salt tolerance selected in the I5 subpopulation.

1146 Table S18. List of 107 IRRI rice samples. Detailing IRRI accession, country on origin, K9 and K15

1147 group and Vietnamese subpopulation.

1149 Table S19. List of 14 SNP sets used for analysis. Detailing filtering parameters, sample and SNP

1150 numbers for each SNP set. 
bioRxiv preprint doi: https://doi.org/10.1101/2020.07.07.191981; this version posted July 8, 2020. The copyright holder for this preprint (which was not certified by peer review) is the author/funder, who has granted bioRxiv a license to display the preprint in perpetuity. It is made available under ACC-BY-ND 4.0 International license.

1152 Table S20. Summary count of SNPs with effects on the genome. Detailing SnpEff annotation of

1153 the full set of 3,750,621 SNPs using the Oryza sativa MSU release 7 rice annotation. Six tables

1154 detailing number of effects by impact, functional class, type, region, base changes and Ts/Tv ratio.

1155 
1158 Figure S1. Analysis of STRUCTURE output using the Evanno method.

1159 Evanno Plots output from Pophelper for 672 Vietnamese samples, 426 Indica samples and 211

1160 Japonica samples.

1161

1162 Figure S2. Mapping rate (\% properly paired) for Japonica and Indica subpopulations.

1164 Figure S3. Principal coordinate analysis (PCO) of the 3,635 Asian cultivated rice genomes.

1165 Plots are coloured by the subpopulations a K9_new, b K15_new. The first component represents the

1166 separation between the Indica and Japonica lines. The second components show the separation of

1167 cAus and to a lesser extent cBas while the third and fourth components represent the separation within

1168 Japonica and Indica respectively. Note for (a) we display the first 3 components and for (b) we

1169 display components 1,2 and 4.

1170

1171 Figure S4. Comparison between K15_3KRGP, K15_new and Vietnamese subpopulations.

1172 a Comparison between K15_3KRGP and K15_new using 3023 samples. b Comparison between

1173 K15_new and Vietnamese subpopulations using 668 samples (overlap of 56 samples from Vietnam

1174 with a). c Percentage of K15_new subpopulations from Vietnam. Arrow are shown for subpopulations

1175 which consist of $>50 \%$ of samples from Vietnam. Diagram generated using http://sankeymatic.com/

1177 Figure S5. PCO analysis of $\mathbf{1 6 0 5}$ Indica samples. Omitting the samples classified as XI-adm and

1178 Ind-adm outside Vietnam for clarity. Plot coloured by a K15_3KRGP, b K15_new including

1179 Vietnamese samples, c Five Vietnamese Indica subpopulations. The ellipses show the 95\%

1180 confidence interval. $\mathrm{X}=\mathrm{PC} 1, \mathrm{Y}=\mathrm{PC} 4, \mathrm{Z}=\mathrm{PC}$. Figure generated using $\mathrm{rgl}$ https://r-forge.r-

1181 project.org/projects/rgl/

1182 
1183 Figure S6. PCO analysis of 982 Japonica samples. Omitting the samples classified as GJ-adm and

1184 Jap-adm outside Vietnam for clarity. Plot coloured by a K15_3KRGP, b K15_new including

1185 Vietnamese samples, c Four Vietnamese Japonica subpopulations. The ellipses show the 95\%

1186 confidence interval. $\mathrm{X}=\mathrm{PC} 3, \mathrm{Y}=\mathrm{PC} 4, \mathrm{Z}=\mathrm{PC}$. Figure generated using $\mathrm{rgl}$ https://r-forge.r-

1187 project.org/projects/rgl/

1189 Figure S7. Admixture components of the Indica I3, I4 and I5 subpopulations.

Figure S8. PCA analysis of Indica and Japonica Vietnamese subpopulations including 51

genotypes from outside Vietnam. a PCA analysis of 445 accessions using the top two components

to separate the five Indica subpopulations. The ellipses show the $95 \%$ confidence interval. b PCA

analysis of 233 accessions using the top two components to separate the four Japonica

subpopulations. The ellipses show the $95 \%$ confidence interval.

Figure S9. Correlation between the 20 phenotypes.

Figure S10. Correlation between Indica and Japonica for the 13 phenotypes used for GWAS.

1200 The figure was created using "ggpairs" package in R.

Figure S11. Correlation between Indica I1 and I5 subpopulations for the 13 phenotypes used for

GWAS. The figure was created using "ggpairs" package in R.

Figure S12. Boxplots showing the Phenotypic distribution per subpopulation for Culm Length,

Grain Length, Grain Width and Heading Date.

Figure S13. Indica subpopulation diversity.

1209 Diversity $(\pi)$ plotted along the 12 rice chromosomes in sliding $100 \mathrm{~kb}$ windows. 
1211 Figure S14. Japonica subpopulation diversity.

1212 Diversity $(\pi)$ plotted along the 12 rice chromosomes in sliding $100 \mathrm{~kb}$ windows.

\section{Figure S15. SNP filtering for heterozygosity}

1215 Proportion of heterozygous calls versus allele frequency. Each dot represents a SNP from a random

1216 sample of 100,000 SNPs. The points have an opacity of 5\% to highlight regions of higher point

1217 density. The bulk of the SNPs lie on the Hardy-Weinberg equilibrium curve scaled by a factor of

1218 around 0.118 , which implies a Wright's inbreeding coefficient of $\mathrm{F}=0.882$. The SNPS have been

1219 filtered using cut off of $0.592\left(5^{*}(1-\mathrm{F})\right)$, the corresponding SNPs which are kept and removed are

1220 shown on the plot.

1221

1222 Figure S16. PCA analysis of 723 samples before and after imputation.

1223 Comparing the 2,690,005 not imputed SNP set 3 to the 2,665,825 imputed SNP set 4

1224 Both SNP set were filtered for 5\% MAF.

1225 Using PC1 and PC2 to separate the Japonica subpopulations. Using PC3 and PC4 to separate the 1226 Indica subpopulations.

Figure S17. GWAS Manhattan and qq plots for the full panel and Indica and Japonica subpanels for

1229 Grain Length, Grain Width, Grain length-to-width ratio, Heading Date, Culm Strength, Leaf Length

1230 and Leaf Width.

1232 Figure S18. GWAS Manhattan and qq plots for the full panel and Indica and Japonica subpanels

1233 for Leaf Pubescence, Culm Number, Diameter Internode, Culm Length, Panicle Length and Floret

1234 Pubescence

1235

1236 Figure S19. Chromosome plots of regions selected in each Indica subpopulation showing the

1237 regions selected against each individual subpopulation and the shaded final selected regions 
bioRxiv preprint doi: https://doi.org/10.1101/2020.07 07.191981; this version posted July 8, 2020. The copyright holder for this preprint (which

was not certified by peer review) is the author/funder, who has granted bioRxiv a license to display the preprint in perpetuity. It is made available under aCC-BY-ND 4.0 International license.

1239 a) 44 regions selected in I1, b) 41 regions selected in $\mathrm{I} 2$, c) 42 regions selected in I3, d) 38 regions

1240 selected in $\mathrm{I} 4$, e) 52 regions selected in I5

1241

1242 Figure S20. Chromosome plots of regions selected in each Japonica subpopulation showing the

1243 regions selected against each individual subpopulation and the shaded final selected regions

1244 which were selected against two subpopulations.

1245 a) 28 regions selected in J1, b) 23 regions selected in J2, c) 24 regions selected in J3, d) 25 regions

1246 selected in J4

1247

1248 Figure S21. Allele Plots showing the "High impact" SNP position within candidate genes. 


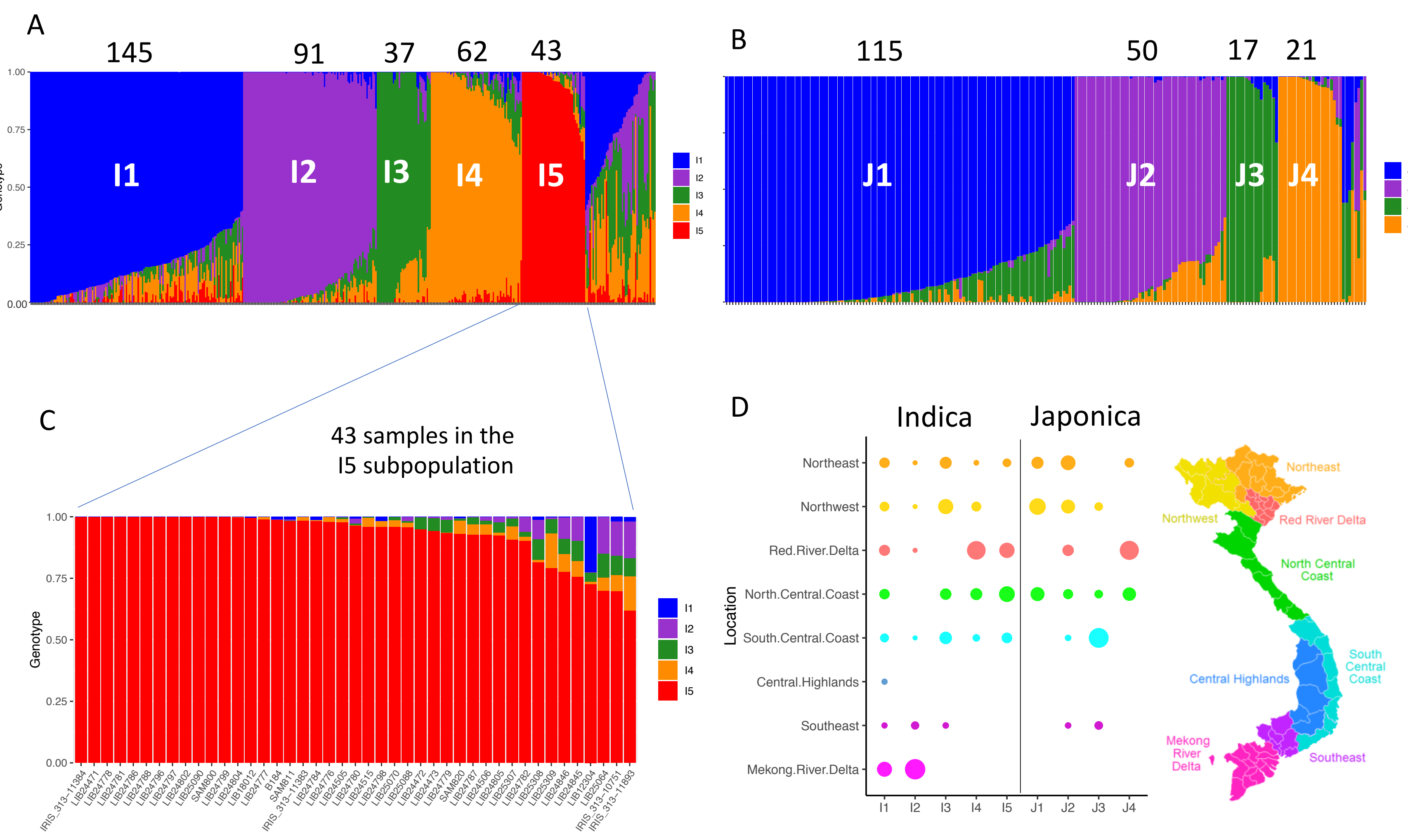


A

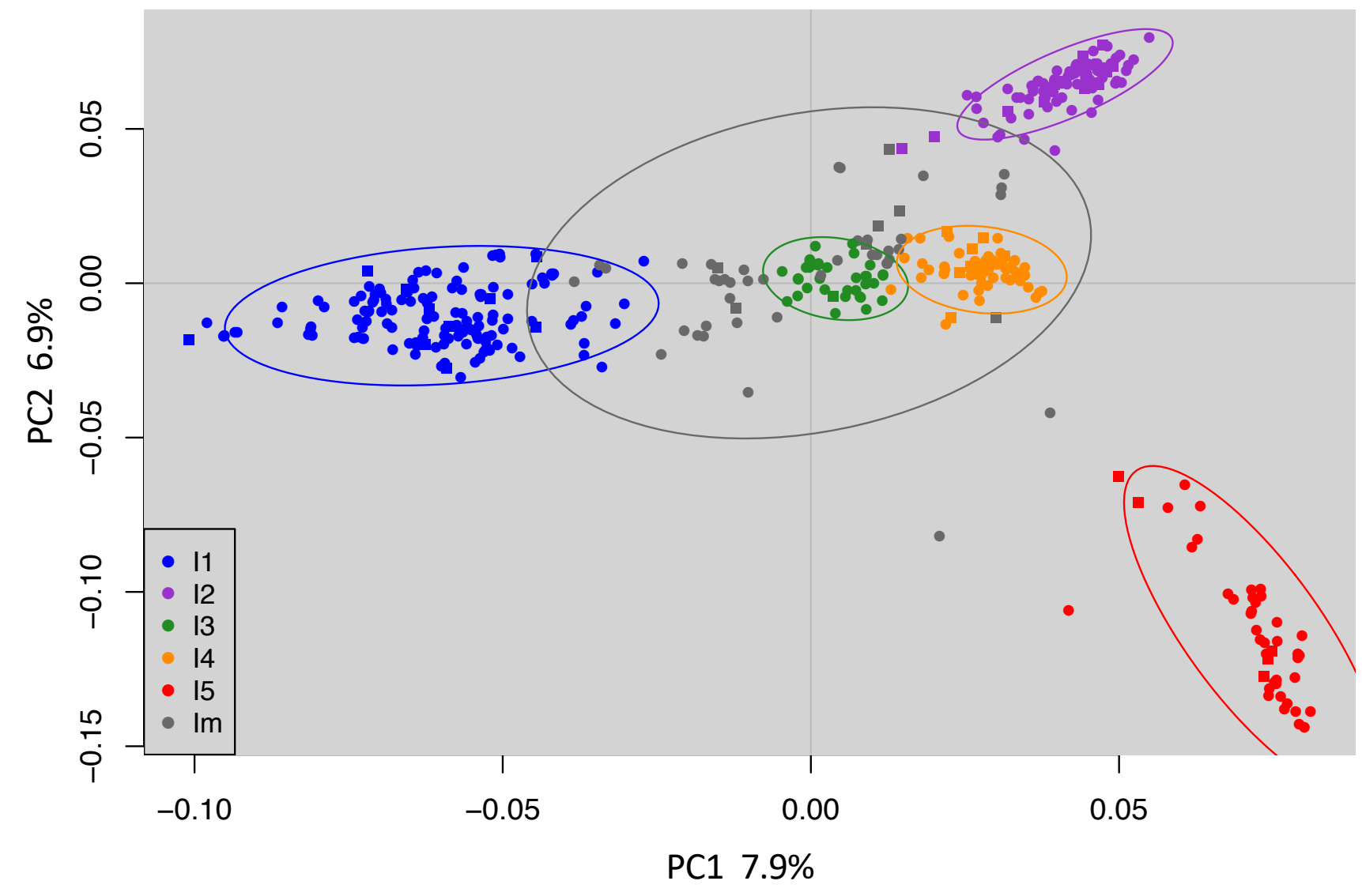

B

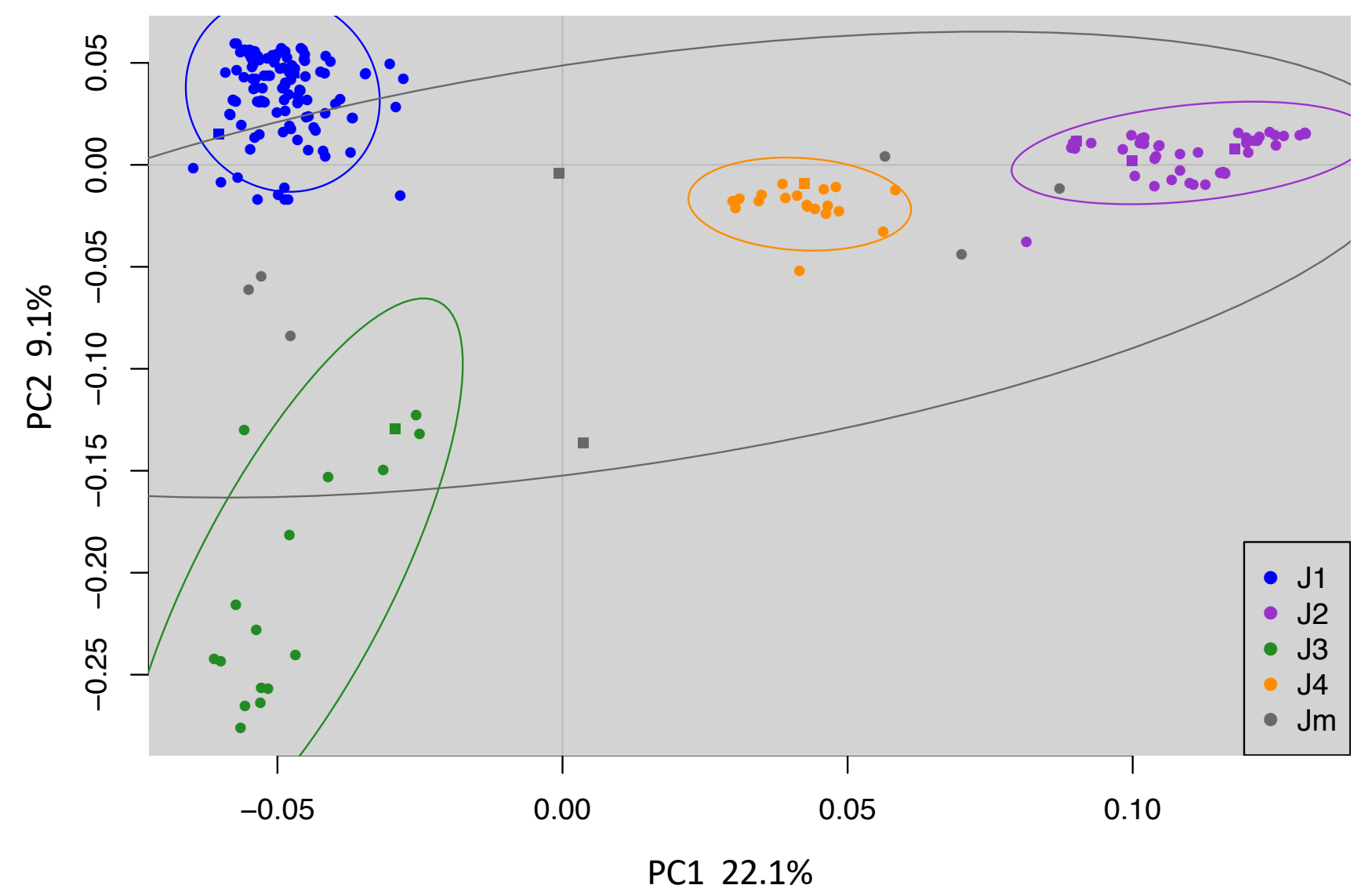

Occessions sequenced in this study

$\square$ Vietnamese genotypes added from 3K-RGP 
A

Ind-2

Ind-3.

Ind-3.2

Ind-3.3

Ind-adm
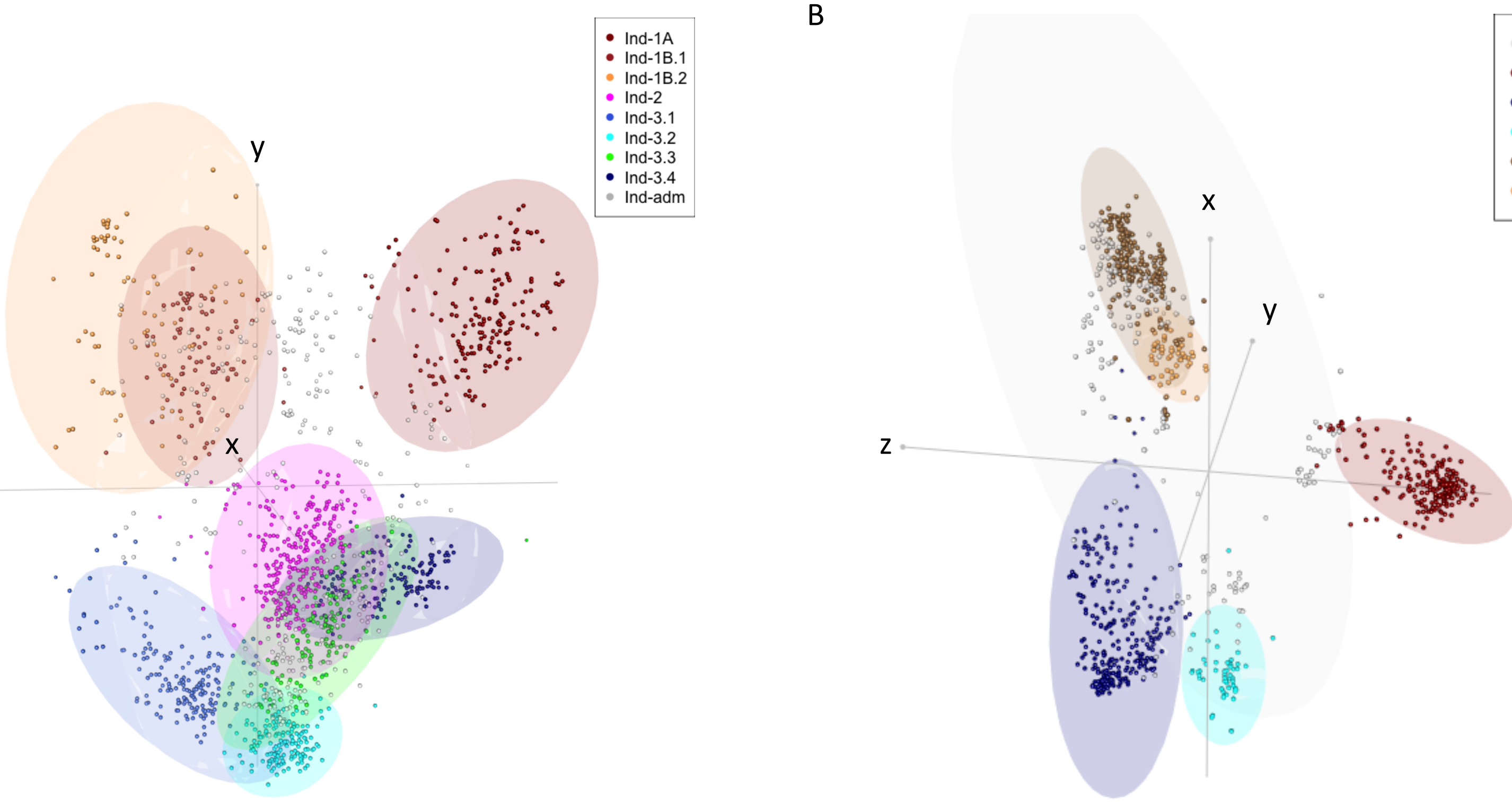

Jap-sbtrp

- Jap-tmp. 1

- Jap-tmp. 2

- Jap-trp.1

- Jap-trp. 2

z 


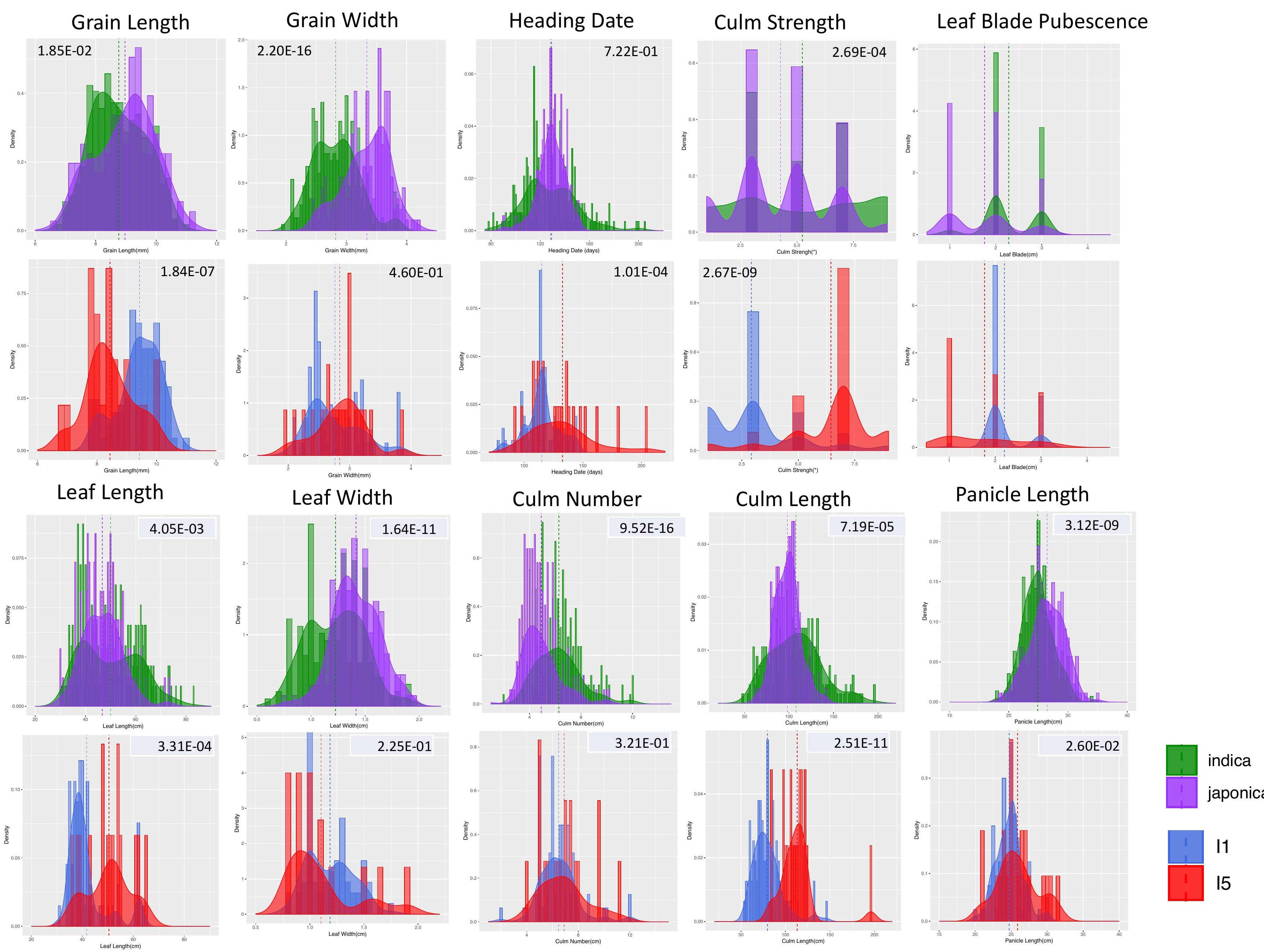




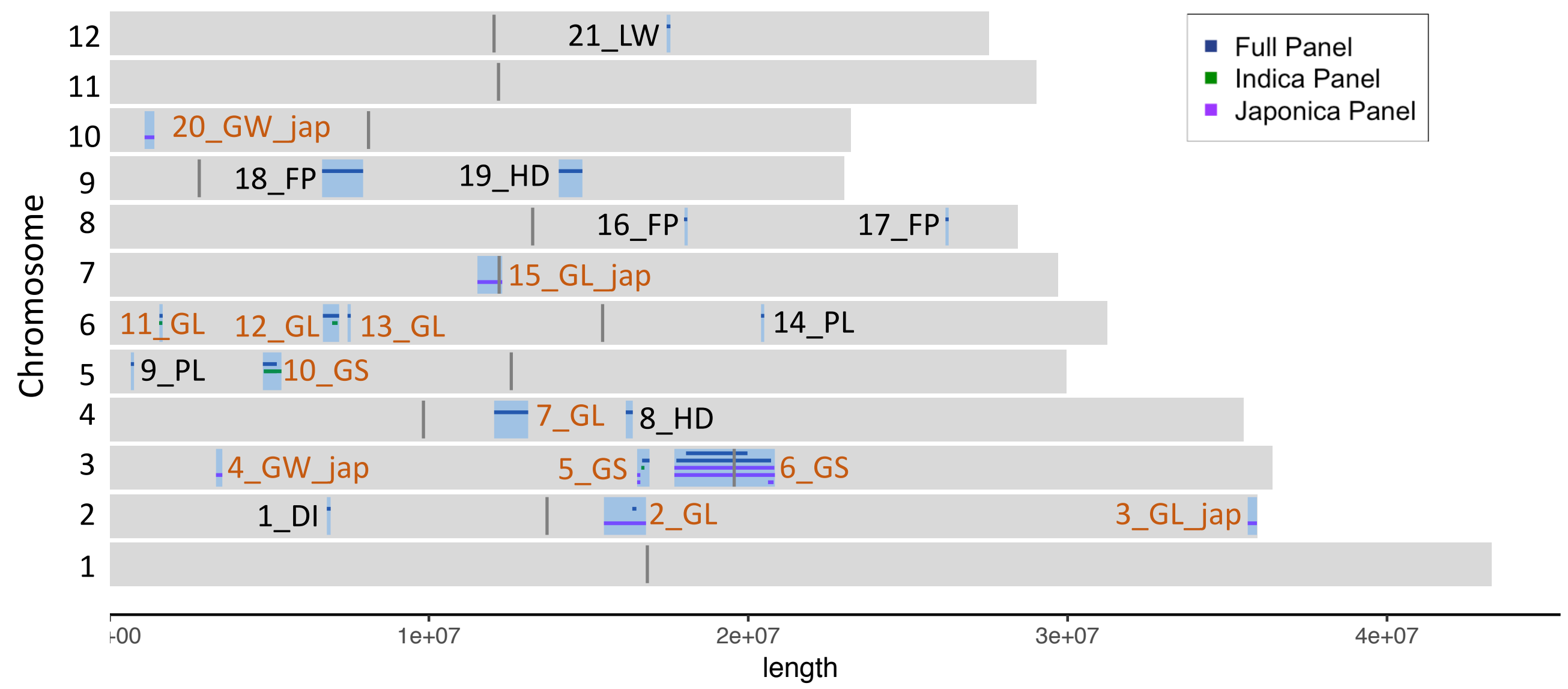




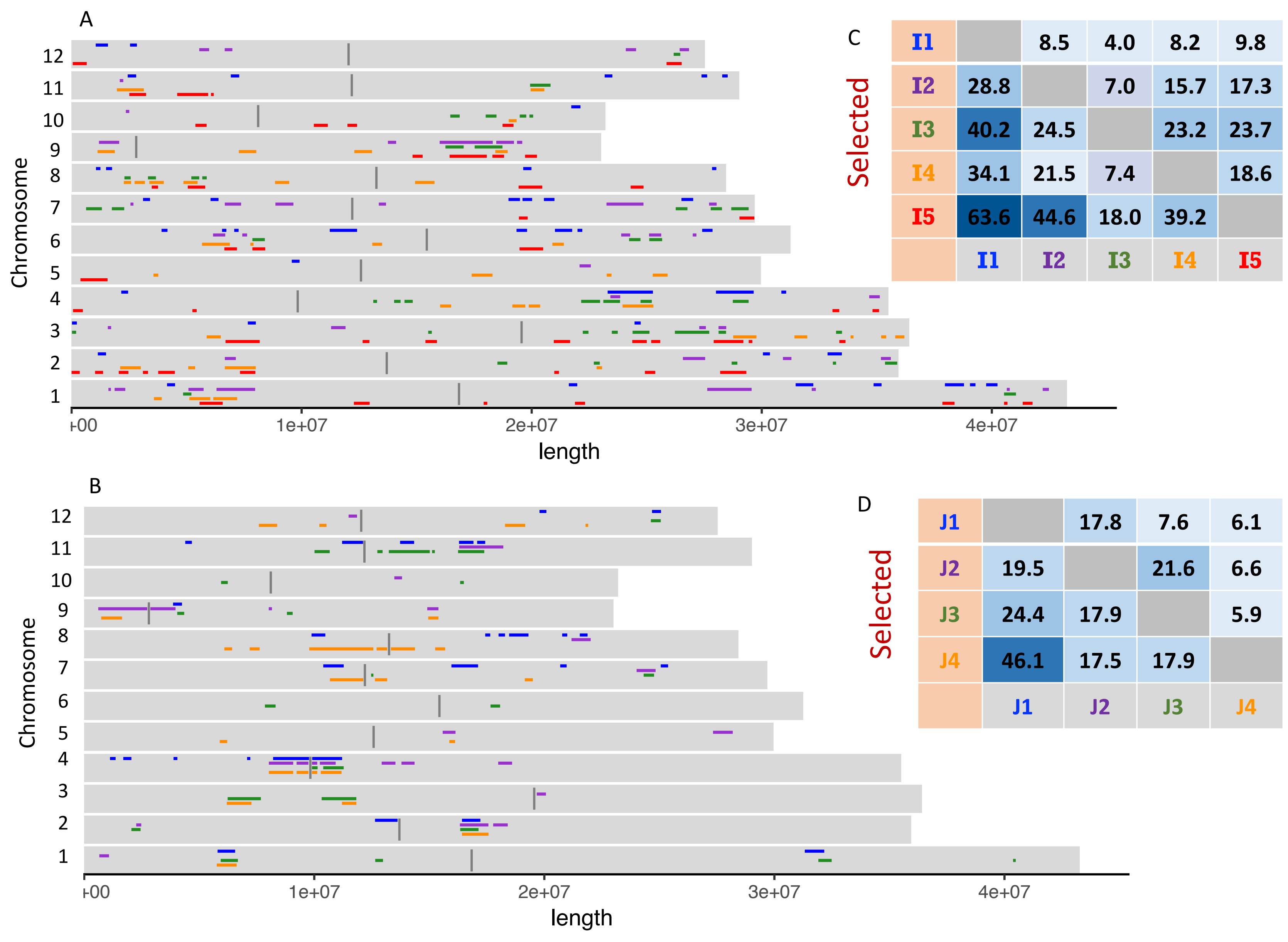




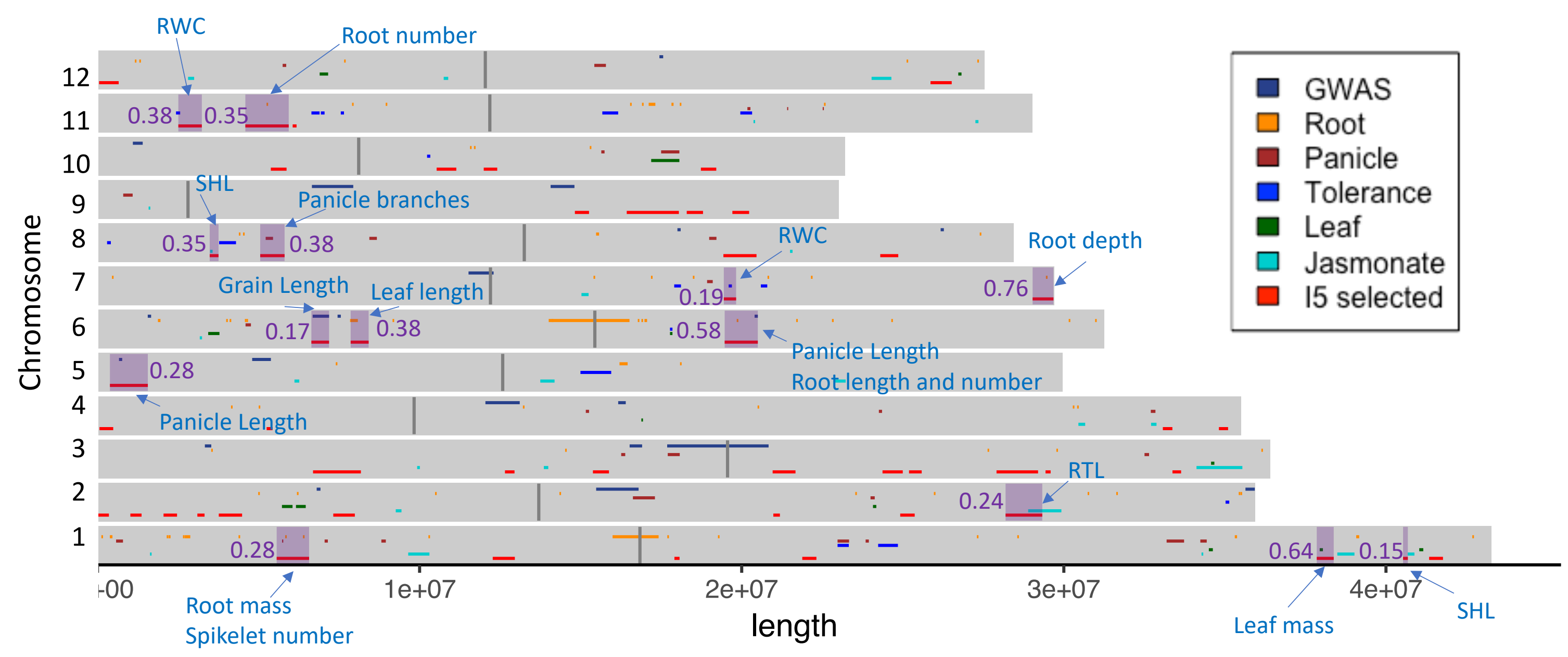

SHL Shoot length in response to Jasmonate RTL Root length in response to Jasmonate RWC Relative water content after drought 